\title{
Saving the environment from the internet: A Polynomial Mitigation Model of Reducing Individual Internet Consumption through Internet Pricing and Environmental Awareness
}

\author{
Ayodhya Wathuge \\ Southern Cross University, Gold Coast, Queensland, Australia \\ ayodhyawathuge@gmail.com
}

\section{Darshana Sedera}

Southern Cross University, Gold Coast, Queensland, Australia

\section{Abstract}

The ever-increasing internet usage purports to make substantial damage to the environment as a result of the emissions arising from the internet supporting infrastructures like data centers. However, there has been much less discussion on creating an awareness of the damage that the internet does to the environment. The purpose of this study is to investigate whether the internet use can be reduced at the individual level by calibrating internet price and one's environmental awareness. The study employs a population-based survey experiment and conducts a polynomial regression analysis using a sample of 326 individuals to understand the conjoined relationship between internet price and environmental awareness. The results indicate that internet price affordability moderated the relationship between environmental awareness and internet usage. Although, before inducing awareness, pricing plays a major role in changing consumption, after inducing awareness the significance of pricing decreases, and awareness tends to determine the consumption. Moreover, the multi-group analysis infers that age does not show any significance on price affordability and environmental awareness, although males display a high price sensitivity and responsiveness towards awareness than their female counterparts.

Keywords: Environmental awareness, internet use, price, polynomial regression, longitudinal survey.

\section{Introduction}

Scientists have demonstrated that there is little time left for the planet Earth to cross the 'pointof-no-return' concerning climate change (Aengenheyster, Feng, Van Der Ploeg, \& Dijkstra, 2018), due to the dangers of increasing temperatures resulting from human actions. A 'code red for humanity' has been issued by the United Nations following a report of the Intergovernmental Panel on Climate Change (IPCC, 2021). Environmental scientists, policymakers, and politicians overwhelmingly agree that creating an awareness of the environmental damage is one of the hardest challenges in the process of creating a sustainable environment (Ghansah, Owusu-Manu, Ayarkwa, Edwards, \& Hosseini, 2021). For example, some studies deny climate change as a 'real' phenomenon (Haltinner \& Sarathchandra, 2021), and some are reluctant to attribute the negative effects of climatic change to human behaviors (Hallegatte, 2009; Jylhä, Tam, \& Milfont, 2020). As such, there has been a wide range of campaigns to create public awareness of the environmental damage such as Earth Hour (Olexsak \& Meier, 2014) and Nowadays green campaign in Malaysia (Islam, Saidur, Rahim, \& Solangi, 2010) that exemplify the importance of creating public environmental awareness. In 
creating such awareness, much of the global attention is focused on the damage caused by transportation, electricity, and fossil fuel combustion (Luís, Vauclair, \& Lima, 2018). Although there have been few discussions on the purported damage that the rising consumption of information and communication technologies (ICT) does to the environment (Salahuddin \& Alam, 2015; Yang, Zhang, \& Li, 2019), studies on how the internet can cause environmental damage are scarce (Hill, Widdicks, \& Hazas, 2020; Widdicks, 2020). Yet, in recognising the potential harm of internet use on the environment, countries, and organisations have taken important steps to reduce the impact of the internet by optimising internet support infrastructures (Goiri, Katsak, Le, Nguyen, \& Bianchini, 2013; UN, 2019). For example, companies with large data centers are taking steps towards using renewable energy, instead of using fossil fuels to operate their data centers (Goiri et al., 2013). Major corporations like Apple, Facebook, and Google have dedicated themselves to sourcing $100 \%$ of their energy from renewables in the future (UN, 2019). Further, providing low-latency mobile services with limited battery power, caching data chunks at optimal edge servers to maximise the integrated utility value, has attracted more attention (Li, Tang, Tang, \& Luo, 2019).

Although technological progress makes information technology (IT) equipment more energyefficient, many studies acknowledge that the rapid growth in internet consumption outperforms the energy efficiency of such technologies, devices, and algorithms (Briscar, 2017; Milne, 2014). For example, the total internet usage in the year 2019 equals to 1.2 billion years, considering the average of six hours of internet use per day (Kemp, 2019). Such high usage contributes to increasing the levels of carbon dioxide $\left(\mathrm{CO}_{2}\right)$. It is expected that $23 \%$ of total $\mathrm{CO}_{2}$ emissions to come from the internet by 2030 (Andrae \& Edler, 2015). The increasing number of internet-based mobile phone usage/addiction (Chi, Hong, \& Chen, 2020; Kuss, Griffiths, Karila, \& Billieux, 2014), increasing internet-based platforms (Kenney \& Zysman, 2020), narrowing of the digital divide (Grishchenko, 2020) and increasing affordability of internet (ITU, 2020) lead to high usage that eventually leads to high levels of pollution. Finally, the global pandemic of COVID-19 has further increased the use of the internet, as more and more individuals and organisations rely on digital engagements. Moreover, the majority of internet users are oblivious to the environmental damage caused by internet use (Aldossary \& Djemame, 2016; Aldossary et al., 2019).

Considering the aforementioned factors, this study is designed to investigate how individual internet consumption can be usefully minimised, thereby reducing the potential damage that it has on the environment. More specifically, this study explores the concomitant roles of (i) awareness and (ii) financial disincentives in reducing individual internet use. It draws the theoretical foundations of the theory of value-belief-norms, where it posits that environmental behaviors are basically generated due to biospheric, altruistic, and egoistic values. According to the literature on pro-environmental behavior (Eriksson, Garvill, \& Nordlund, 2006; Jakovcevic \& Steg, 2013), such values can be awakened using variables such as awareness and financial disincentives.

This study draws its inspirational foundations from the past studies of analogous disciplines such as anti-smoking, drug and alcohol, and road safety that have demonstrated the effectiveness of employing awareness and financial disincentives to modify human behaviors (Petrunoff, Rissel, Wen, \& Martin, 2015; Pope et al., 2020). The use of the internet is conceptually comparable to these disciplines, given that they provide heightened sensations and are addictive in nature (Curry, Wagner, \& Grothaus, 1991; Lee, Han, Kim, \& Renshaw, 
2013; Thombs \& Osborn, 2019). However, we observed that past IS studies, regardless of the context and certainly not in green-IT (Chen, Hui, Su, Fang, \& Hui, 2017; Shuja et al., 2017), rarely employed both awareness and financial disincentives together. Studies suggest that the simultaneous employment of both awareness and financial disincentives (like pricing) could lead to substantial attitudinal changes, compared to using only one of them (Haque, Ahmend, \& Rahman, 2013; Shuja et al., 2017; Verdonk-Kleinjan, Candel, Knibbe, Willemsen, \& de Vries, 2011). In this paper, we investigate the combined and simultaneous approach of using awareness and financial disincentives to lower internet use (i.e., human behavior). As mentioned, such strategies are commonly employed in anti-smoking, drug and alcohol, and road safety campaigns (Chen et al., 2020; Izquierdo, Ramírez, McWilliams, \& Ayuso, 2011; Verdonk-Kleinjan et al., 2011). Drawing parallels with such contexts, we develop a competing model of awareness and financial disincentives to reduce internet use. We argue that combining awareness and financial disincentives would make necessary changes to the individual behavior concerning internet use - thereby reducing its damage to the environment (Hobman \& Frederiks, 2014; Stern, 1999). However, such interventions must be carefully employed (Kollmuss \& Agyeman, 2002; Whitmarsh \& O'Neill, 2010). Typically, in consumer marketing and economics, consumption is manipulated through a delicate combination of price (of the product or service) and awareness (Henriksen, 2012). However, with the reducing prices of internet service provision (ITU, 2020), we are yet to determine the combined role of financial disincentives (i.e., internet price) and increased awareness in changing human behaviors (in this case, reducing internet use). Therefore, the primary objective of this study is to determine the combined effect of internet price sensitivity and environmental awareness to minimise one's internet usage. The study further assesses the effects of age and gender on the aforementioned relationship.

This paper is structured as follows. The paper commences with a literature review, followed by hypotheses development. Next, the theoretical model, experiment design and sample, and methods of analysis are explained. Subsequently, the results of the analysis are provided followed by a discussion on the application of the framework identified. Finally, the paper concludes with the conclusion, limitations, and future research implications.

\section{Literature Review}

This section of the paper provides succinct information about the literature the study is based on. First, it provides a brief on the environmental damage internet usage causes. Then, a discussion takes place on how awareness and financial disincentives can reduce internet usage thereby minimising the environmental damage. This discussion is done by referring to the related literature from other similar contexts. Pricing and awareness have been used in various contexts such as sales, retail, and supply chain for a long time to alter the behaviors of consumers. However, we looked at contexts where a substantial change of behaviors has taken place through manipulation of pricing and awareness strategies, because we consider the usage of the internet as an environmentally harmful behavior that resembles certain aspects of pervasive behaviours, we considered such as addiction. The section ends by summarising the literature on awareness and pricing as the two intervention pathways to reduce internet usage. 


\subsection{Environmental Damage of the Internet}

The following explanation provides a short introduction to the primary energy consumption areas of the internet. Further, it introduces some internet applications and their future usage predictions that create alarming consequences on the environment.

Internet is mainly composed of three infrastructures: data centers to store and process data, network equipment to carry data, and end-user devices to view and give commands (UN, 2019). Each data center is a service provider that provides data and related information services including applications, facilities, networks, servers, and storage resources making it the core infrastructure of the internet (Schulz, 2016). By 2019, the number of data centers increased to 8.4 million (Liu, 2019), supporting internet services through undisturbed, zerodowntime operations (Khalaj, Scherer, Siriwardana, \& Halgamuge, 2014). The power required for data centers is generated through electricity (Zimmermann et al., 2012), while cooling is done using both water and electricity (Zhang, Wang, \& Wang, 2012). Data center electricity consumption is growing 30\% annually due to the drastic demand increases in internet services, making it the fastest-growing end-use of electricity (Han, Coles, Price, Gadgil, \& Tschudi, 2019). Therefore, through data center operations, a huge amount of $\mathrm{CO}_{2}$ is emitted as electricity is mainly generated through non-renewable sources. While companies like Google (2019) have committed to renewable energy for data centers, it has only a small percentage of the total global internet usage.

Moreover, internet applications too are gaining high ubiquity. There are approximately 4.48 billion internet users in the world, reaching nearly $60 \%$ of the global population (Clement, 2019). It is expected that in a few years, the internet will be available to the total global population. Moreover, the emergence of technologies like SMAC-IoT (Social media like Facebook; Mobile applications; Analytics available even to the consumer; Cloud services that offer near-zero or free storage and the predicted growth of Internet-of-Things) further increase the negative impact of the internet on the environment. According to research done by Statista (2019), by 2025 the total IoT connected devices are expected to reach 75.44 billion worldwide, which is a fivefold increase in ten years. Such developments will further increase the individual consumption of the internet and internet services. As such, the awareness of its potential damage to the environment becomes ever more important. For example, a simple behavioral change like downloading vs. streaming, frequency of checking of social media, unnecessary and spam emails beg the question of the impact of individual internet practices.

Therefore, it is worth reducing individual internet consumption. In doing so, we looked at previous studies that have used pricing and awareness to reduce socially confined behaviors, to identify types of pricing and awareness strategies.

\subsection{The Role of Awareness in Changing Human Behavior}

Among many factors that generate behaviour change, awareness appears as one of the most primary and important change agents. Many behaviour change frameworks consider creating awareness as the first step in modifying behaviour (De Vries et al., 2003; Jenkin, Webster, \& McShane, 2011). Therefore, in contexts such as anti-smoking, drink driving, and speed driving awareness is being used as a prominent strategy to change behaviour.

Past studies in the anti-smoking context use different types of awareness campaigns to reduce the initiation and continuation of smoking. Counter industry media campaigns raise awareness of persuasive intent of protobacco messages empowering individuals to be less 
receptive to tobacco promotions (Hershey et al., 2005; Syu, Huang, \& Huang, 2010). In a longitudinal study, Hershey et al. (2005) show that teens became less receptive to tobacco promotions with a counter-industry media campaign. They show that teens who received a higher level of campaign exposure displayed more negative beliefs about tobacco industry practices and more negative attitudes towards the tobacco industry leading to low receptivity to protobacco advertising which showed less progression towards smoking intentions and behaviour. Moreover, past studies show that creating awareness of the benefits of quit smoking along with the consequences of smoking leads to reduce adult smoking depicting that people in higher age brackets are responsive to awareness (Brewer et al., 2016; Farrelly et al., 2017).

Studies show that awareness is a significant factor in reducing drink driving (Lewis, Watson, \& White, 2008; Nathanail \& Adamos, 2013; Sheehan et al., 1996). Sheehan et al. (1996) show that interactive educational programs that provide confidence to face pressures by replying to persuasive arguments and alternative strategies to avoid drink driving helped improve current social attitudes and behaviour change. However, employing an experimental approach Nathanail and Adamos (2013) show that drivers who were exposed to communication campaigns that create awareness of the permissible alcohol level while driving and risks of drink driving showed no significant effect in controlling the behaviour.

Moreover, significant behaviour changes can be observed in speed driving contexts (McKenna, 2007; Poulter \& McKenna, 2010; Ranjit, Snyder, Hamilton, \& Rimal, 2017). Poulter and McKenna (2010) and McKenna (2007) using a sample of school students show that educational interventions improved pre-driver road safety beliefs including speed driving.

This summary concludes that awareness creates a significant impact on behaviour change although a few studies do not. However, the positive behaviour change outperforms the neutrality in behaviour for awareness.

Although there are studies in other contexts incorporating awareness, the studies conducted related to individual internet usage and sustainability are very limited. Studies have developed several frameworks related to green IT/S, and they acknowledge the importance of creating an overall awareness of energy conservation and carbon emissions facilitating green IS practices (Elliot \& Binney, 2008), contextual factors affecting green assimilation (Cooper \& Molla, 2014), green IT readiness models (Molla \& Cooper, 2010) and trends and patterns related to green IT (Sedera, Lokuge, Tushi, \& Tan, 2017). Moreover, studies have developed instruments to measure the environmentally sustainable IT performance drivers (Molla, 2013). However, the studies based on these frameworks address only the national and organisational level strategies to minimise internet damage. Past studies suggest that creating awareness at the societal level or the individual level is critical and however, is sparse (Jenkin, Webster, et al., 2011). Further, studies suggest that even organisations are in 'infancy stages of awareness' of Green IT/IS practices, implying that awareness of environmental pollution of the internet is very low (Jenkin, McShane, \& Webster, 2011). Few studies have been conducted in information systems literature promoting eco-sustainable behaviours by employing gamification techniques (Seidler et al., 2020), human-computer interaction techniques (Hill et al., 2020; Widdicks, 2020) and an awareness strategy (Wathuge \& Sedera, 2021) to reduce the individual internet usage to minimise the climate change. However, there are no studies that investigate the combined effect of awareness and another strategy. Therefore, leaning on literature we 
investigate the effect of awareness on internet usage to test whether it creates an impact on behaviour. The hypothesis is;

H1: Increased environmental damage awareness creates a positive impact on reducing internet usage.

\subsection{The Role of Price in Changing Human Behaviour}

Pricing also plays a major role in changing human behaviour. It is being used to motivate as well as demotivate individuals in engaging in certain behaviours (Aebli, Volgger, \& Taplin, 2021; Ball et al., 2011). Pricing acts as a deterring agent in the contexts of anti-smoking, drinkdriving, and speed driving. Past studies show that pricing creates an immediate impact on behaviours.

Moreover, anti-smoking literature summarises that imposing new taxes on cigarette packets as well as increasing existing taxes lead to reduce smoking (Ferrer, Orehek, Scheier, \& O'Connell, 2018; Pope et al., 2020; Verdonk-Kleinjan et al., 2011). In a study to decrease the cigarette demand, while increasing the demand for a substitute, Pope et al. (2020) show that taxes on cigarettes play a major role in reducing the demand for cigarettes while increasing the tendency towards using the substitute. Moreover, investigating tax increases of cigarette packets over a long period, Ferrer et al. (2018) conclude that increase in taxes has a substantial effect on the consumption of cigarettes among smokers low in behavioural disengagement.

Price regulations related to drink driving and speed driving are mainly imposed as fines. According to past studies, the amount of fine is determined by the blood alcohol level (Nagata, Setoguchi, Hemenway, \& Perry, 2008) for drink driving, and exceeded speed range or offence history (Delhaye, 2007) for speed driving. Nagata et al. (2008) show that by decreasing the permissible blood alcohol level and increasing penalties, large and immediate public health benefits measured through factors such as alcohol-impaired traffic injuries, alcohol-impaired severe traffic injuries, and alcohol-impaired traffic fatalities per billion kilometers driven can be observed. Similarly, Izquierdo et al. (2011) demonstrate that introduction of a penalty point system based on the exceeded speed limit to control road accidents due to irresponsible driving resulted in decreasing the number of fatalities. These studies extracted from the past literature show that pricing strategies employed according to the severity of offence were effective in changing behaviour resembling prohibitive behaviour interpretations.

When studying the types of pricing strategies, we could observe that past studies have used different types of pricing models. The primary pricing models identified are flat-rate, blockrate, and volume-based pricing (Chen et al., 2020).

In relation to internet pricing, researchers have investigated economic (Bateni, Hajiaghayi, Jafarpour, \& Pei, 2011; Lv \& Rouskas, 2010) and network congestion (Nevo, Turner, \& Williams, 2016; Sen, Joe-Wong, Ha, \& Chiang, 2015) specific pricing strategies to maximise profits and to increase resource utilisation which lacks the environmental perspective. Near zero internet prices increase the internet demand exponentially, and more importantly, it creates irresponsible internet practices such as unattended music or video playing, addictive social media usage, and addictive online gaming behaviours. Therefore, it is of high necessity to determine the effect of internet price changes on internet usage to eventually reduce its negative environmental impact. Therein, owing to the past studies we test the hypothesis,

H2: Increased internet pricing creates a positive impact in reducing internet usage. 
As described earlier, awareness is an important factor that creates changes in the behaviours of smokers, drink and speed drivers. However, some studies show that the effect awareness alone creates is not significant in modifying the aforementioned behaviours (Nathanail \& Adamos, 2013; Schaap et al., 2008; Steptoe et al., 2002). Steptoe et al. (2002) show that risk awareness inconsistently relates to smoking behaviour in countries that have lower education and economic levels (Verdonk-Kleinjan et al., 2011). Moreover, highly addicted substance users show low or no response to awareness. To enhance the relationship between awareness and behaviour change in instances such as the ones mentioned above, scholars suggest using more than one strategy (Frieden et al., 2005; Giesbrecht \& Greenfield, 2003; Verdonk-Kleinjan et al., 2011). Studies have used pricing as a strategy to enhance the effects that awareness creates on human behaviour (Oguchi, 2016). Similarly, to enhance the impact of awareness on internet usage we use the price variable as a moderator of the relationship between awareness and internet usage. If financial disincentives significantly influence behaviour change, it follows that financial disincentives will have a significant moderating role in the relationship between awareness of environmental damage and behaviour change. Therefore, the hypothesis is;

H3: Increased internet pricing moderates the relationship between environmental damage awareness and internet usage.

As observed above, changes to human behaviour in smoking, drink driving, and speeding have been achieved through a combined effort of both pricing and awareness. As stipulated in hypothesis 3, we also argue that the combined effect of internet pricing and environmental awareness would minimise the use of the internet. However, we recognise that such a combination in this context is likely to yield a spectrum (or a continuum) of types of behaviours, rather than a unified behaviour. Past studies show that behaviours concerning price can be (i) resource exploitive, where the consumer engages in maximising his utility by exploiting the resources (Watts \& Zimmerman, 1978), (ii) principle and value-based, where principles and values acquire a major proportion in an individual's cognition than existing practical conditions (Kivetz \& Tyler, 2007), (iii) logical, where the behaviour is logically true to existing logical interpretations Priem and Butler (2001) and (iv) prohibitive, where external prohibitive factors like price discourage intention to behave (Liang, Farh, \& Farh, 2012; Lin \& Johnson, 2015).

\subsection{Theoretical Foundations}

A fundamental premise of consumer behaviour is that a consumer develops certain attitudes towards products or services that would lead to actual behaviours (Luchs \& Mooradian, 2011). Multiple approaches have emerged to explain the progression from attitudes, such as awareness (Brounen, Kok, \& Quigley, 2013) and price consciousness (Alford \& Biswas, 2002), that lead to behaviours. For example, the theory of planned behaviour, social identity theory, means-end theory, and norm activation model, which was later extended to create the valuebelief norm (VBN) theory can be named as a few. VBN theory is selected as the theoretical premise of this study. VBN theory is a theory of environmentalism which is built on the causality of five variables: human values (biospheric, altruistic, and egoistic) which influence environmental cognitions, new ecological paradigm - belief that human actions deteriorate the environment quality, awareness of consequences of human actions on the environment, the ascription of responsibility that oneself should take actions to protect the deteriorating 
values, and building up a sense of personal obligation to act upon the ascription of responsibility, which leads to actual behaviour (Stern, Dietz, Abel, Guagnano, \& Kalof, 1999).

VBN theory has been extensively employed in studies on the socio-psychological perspectives of environmentalism (Liobikienė \& Poškus, 2019; Stern, 2000), where defined behaviourally as the propensity to take actions with pro-environmental intent. The importance of choosing VBN theory as the philosophical lens of our study lies in a few factors. Firstly, unlike other theories, it precisely recognises that individual behaviour may also be rooted in altruistic or biospheric values. This helps in profoundly grasping our study's core idea well. That is the mitigation of internet consumption despite economic benefits that occur from one's egoistic values. The theory supports the ascription of responsibility for things an individual value personally, and shows the causal relationship of how personal values, beliefs, and norms shape pro-environmental behaviour. Secondly, the VBN theory postulates a mechanism: norm activation, which can decrease 'rational utility calculus' considered in most 'subjective utility logic': the economic advantage of an opportunity, on which most other theories are based (Stern, 1999). In proving that Stern states, processes that bypass subjective utility are important for understanding behaviours that lack egoistic justifications, whereby an individual act selflessly without expecting any personal benefit like such we expect from the internet users. Therefore, we chose the VBN theory which most accurately provides the philosophical lens to our study.

The VBN theory which the study is based on has been used in several instances to investigate the effect of awareness and pricing on behaviour (Eriksson et al., 2006; Jakovcevic \& Steg, 2013). Pricing is a measure of sacrifice for individuals in purchasing a product/service (Zeithaml, 1988). As such, it provides market signals to change the demand or supply. VBN theory shows that monetary aspects which determine egoistic values at times prevent the execution of pro-environmental actions. For example, (López-Mosquera \& Sánchez, 2012) show that egoistic values negatively affected the willingness to pay for conservation. However, the same value can be used to restrict individuals from performing environmentharming actions (Eriksson et al., 2006; Sahin, 2013). On the other hand, awareness can be used to heighten the biospheric and altruistic values of an individual (Eriksson et al., 2006; Jakovcevic \& Steg, 2013; Pooley \& o'Connor, 2000). It would change the attitudes, activate personal norms, and moral obligations towards the target behaviour (Ebbs, Dahlhaus, Barton, \& Kandra, 2018; Pooley \& o'Connor, 2000). Therefore, using a combination of pricing and awareness would heighten the values of individuals, and as they are complementary in nature and not substitutes, putting them together would generate environment-friendly results. Through his studies, Stern (2000) makes several recommendations, where he proposes investigating the causal relationships of 'personal financial capabilities', 'general environmentalist predispositions', and 'change in lifestyle' around which our study is based. The VBN theory has been used in several instances to investigate the effect of awareness and pricing on behaviour (Eriksson et al., 2006; Jakovcevic \& Steg, 2013). There are different types of pricing strategies for the internet such as flat-rate strategy, block-rate strategy, and volumetric rate strategy that are specifically location-wise popular. Through the study, we observe the behaviour outcome of internet users by considering the affordability of internet pricing and environmental awareness.

The research model, embedded in the study design depicted in Figure 1 shows how the effects of personal financial capabilities (measured using 'price affordability' (Fan, 2005)) and 
environmental predisposition (measured using the 'environment awareness' (Arlt, Hoppe, \& Wolling, 2011)) changes the lifestyle through pro-environmental intent measured using the 'internet usage' (Abrahamse \& Steg, 2011). Therein, the independent variables are price affordability and awareness while the dependent variable is internet usage.

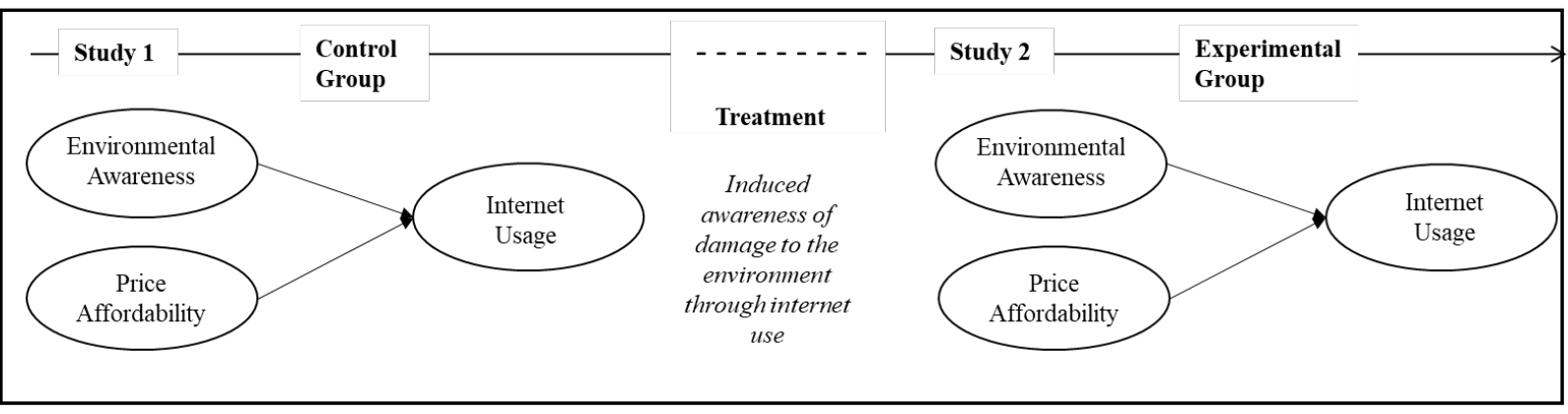

Figure 1. Study Design

\section{The Experiment Design and Sample}

A population-based survey experiment was used as the method that allows the combination of the causal power of experiments and generalisability of population-based samples (Mutz, 2011). Population-based survey experiments possess the design of an experiment, while a survey is embedded to capture the data from a representative population-based sample.

The experiment was conducted online as the method allows to conduct it remotely. To test the model, a survey consisting of questions related to before and after effects of awareness, pricing, and internet usage was employed. The survey consisted of questions related to demographic characteristics of respondents, awareness of internet damage on the environment: measured using the perception they hold on to environmental damage their internet usage cause, and price affordability: measured using perception about prices of internet data packages and their affordability. Further, we included questions related to internet usage: measured using time spent on the internet, the probability to change current usage pattern, frequency of use, and addiction to it. A Seven-point Likert scale ranging from 1- Strongly Disagree to 7- Strongly Agree was utilised to capture the responses.

After the Study-1 control group survey data collection was completed, we induced the subjects with a tailor-made video of four minutes about the damage that internet consumption does to the environment. To test the effects of the treatment, subjects were provided with the same survey again. It included questions to assess the attitudinal change that occurred after watching the video. There, the current intention to use the internet was questioned. Therein, we test the simultaneous roles of the targeted awareness campaigns (Maibach, 1993) and pricing (Fan, 2005), which are purported to be altering behaviours. The experiment was fielded within 15 days (McGinty, Goldman, Pescosolido, \& Barry, 2015; McGinty, Webster, \& Barry, 2013; Pedulla \& Thébaud, 2015). Treatment effects were measured by the difference between the level of awareness, price sensitivity, and internet usage of the control group and experimental group.

\subsection{Treatment}

Through keen observation of several videos, we selected a video published by a public news channel of France named France 24 on YouTube (France24, 2017), as it contained relevant content proved in the literature that could create awareness, and also the video length was appropriate. The video provided information about the amounts of $\mathrm{CO}_{2}$ emissions of most 
popular internet-based activities such as circulating emails and web searches. Moreover, it defined the concept of data centers and their energy requirements. Overall, the video provides a succinct awareness of the damage internet does to the environment. To capture the number of people who have watched the video before and after the questionnaire was provided, we kept a count on the number of YouTube views. Figure 2 frames provide three captures to show the content of the video.

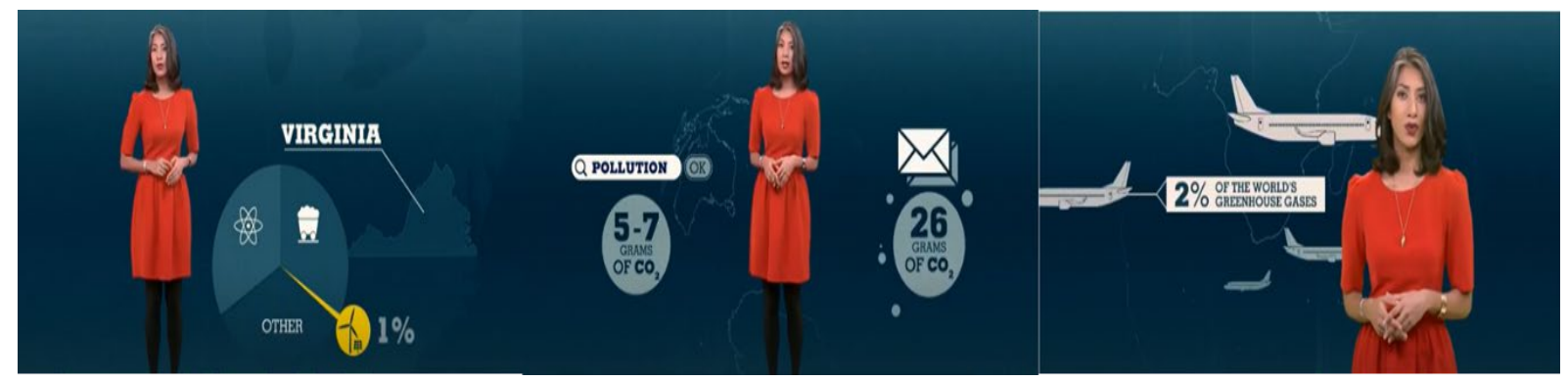

Figure 2. Screen captures of the video

\subsection{Measures}

We adapted survey questions, by reviewing literature related to the constructs and identifying different ways that they can be conceptualised to best capture the aspects of price affordability, awareness, and internet usage. Further, we assured that the questionnaire includes questions that acquire necessary inputs that we need to measure in the analysis acquiring content and face validity (Lawshe, 1975). Questions related to measuring awareness were adapted from studies such as (Bulgurcu, Cavusoglu, \& Benbasat, 2010; Morgil, Seçil, Seçken, Yavuz, \& Oskay, 2004; Yucedag, Kaya, \& Cetin, 2018). Questions related to pricing were derived and adapted from (Kuruzovich, Viswanathan, Agarwal, Gosain, \& Weitzman, 2008; Zettelmeyer, Morton, \& Silva-Risso, 2001), and questions related to internet usage were derived from (Mathwick \& Rigdon, 2004; Venkatesh, Brown, Maruping, \& Bala, 2008).

\subsection{Sample}

The population considered for the study was global internet users. To test the model presented in Figure 1, a representative sample was drawn from the sample frame of ordinary internet users of Sri Lanka. According to Kothari (2004), the sample frame should be represented in a "list". However, lists that contain details of general internet users are not available (Fricker, 2008). Furthermore, list-based sampling frames such as university email lists, email lists of organisations may restrict the sample to specific characteristics such as highly educated or financially strong subjects (Fricker, 2008). Therefore, we distributed the link of the questionnaire randomly among the internet users we meet and through social media accounts such as Facebook, LinkedIn, and Instagram to reduce the sample biasness. Moreover, we encouraged the receivers of the questionnaire to distribute it randomly among the internet users they meet. In selecting the sample, we used stratified sampling technique to stratify the population according to gender. The global internet user gap of male vs female is $17 \%$ as per the International Telecommunication Union (ITU, 2019). That means males who use the internet are approximately higher by $17 \%$. Henceforth, we randomly recruited male and female respondents that match the above statistic by distributing the survey link among the Sri Lankan internet users. Finally, we acquired a sample of 326 internet users. According to our sample, the gap between internet using males (58.3\%) and females (41.7\%) was $16.6 \%$ which approximately equaled the global internet user gender gap. 
A larger sample would be more appealing to the generalisation of the results. However, the current sample does well represent the global internet users who use the internet on average 6 hours and 42 minutes a day (Kemp, 2019) which approximately resembles Sri Lanka's average internet usage time (Kemp, 2019). The majority of the respondents in the sample are young adults. Therefore, the sample represented a trustworthy number of major internet users, because global internet usage is more skewed towards young adults and their general awareness is low (Clement, 2020; Thilina, Guruge, \& Nanayakkara, 2020). It was necessary that the sample comes from a single geographical area, have a similar educational background, and have similar economic conditions to increase the homogeneity and to control the effect of extraneous variables. Therefore, internet users based in Sri Lanka were derived. Moreover, in selecting the sample, we looked at a location where people are more price sensitive and literate as we observe price sensitivity and awareness. Due to price fluctuations, price sensitivity can be easily identified. Moreover, the price model is also sought in the sample. Developed countries have flat-rate pricing and price-sensitivity varies based on the price model. Based on these factors we selected Sri Lanka which is a developing country that has a high literacy rate. Further, the country offers block-rate pricing where price sensitive internet users are prominent.

The demographics and categorical values derived through the survey are summarised in Table 1 below. The categories were created by using the original input of each survey respondent, without making any adjustments or modifications.

\begin{tabular}{|c|c|c|c|c|c|}
\hline Age & $\#$ & $\%$ & Internet access & $\#$ & $\%$ \\
\hline Below 25 & 75 & 23 & Limited & 266 & 82 \\
\hline $26-40$ & 240 & 74 & Unlimited & 60 & 18 \\
\hline Above 41 & 11 & 3 & \multicolumn{3}{|c|}{ Cost of the internet package } \\
\hline \multicolumn{3}{|l|}{ Gender } & \multirow{7}{*}{$\begin{array}{l}\text { Below } 1000 \text { LKR }^{1} \\
1001 \text { - } 2000 \text { LKR } \\
\text { Above } 2001 \text { LKR }\end{array}$} & \multirow{7}{*}{$\begin{array}{l}91 \\
149 \\
86\end{array}$} & \multirow{7}{*}{$\begin{array}{l}28 \\
46 \\
26\end{array}$} \\
\hline Male & 190 & 58.3 & & & \\
\hline Female & 136 & 41.7 & & & \\
\hline \multicolumn{3}{|c|}{ Internet connections } & & & \\
\hline Mobile & 68 & 21 & & & \\
\hline Home & 26 & 7 & & & \\
\hline Both & 236 & 72 & & & \\
\hline
\end{tabular}

Table 1. Demographics and Categorical Values

Note: ${ }^{1}$ LKR is the currency of Sri Lanka

When doing the analysis, we considered several control variables, that are extraneous variables not linked to the hypotheses and theories being tested (Spector \& Brannick, 2011). They are the geographical location and price model. By selecting Sri Lanka, we have controlled the effects of geographical location and price model on the hypotheses being tested. The effects of age and gender on internet usage are calculated in the multi-group analysis in a later section.

\section{Analysis and Results}

For the analysis, we employed three types of tests: partial least squares (PLS) structural equation modeling (SEM) method (Benitez-Amado, Henseler, \& Castillo, 2017; BenitezAmado, Llorens-Montes, \& Fernandez-Perez, 2013), multi-group analysis (MGA), and polynomial regression (Atwater, Waldman, Ostroff, Robie, \& Johnson, 2005; Edwards \& Parry, 1993) with response surface methodology (Box \& Draper, 1987; Cornell \& Khuri, 1987). The PLS analysis was employed to validate the constructs and derive the MGA, while the 
polynomial regression and response surface analysis were used to understand the interplay between price and awareness towards internet usage in the control and experimental groups of the study. The PLS-SEM is well suited for highly complex predictive models, which supports the mapping of formative observed variables (Henseler \& Sarstedt, 2013; Sedera, Gable, \& Chan, 2003; Wold, 1989). When conducting polynomial regression and response surface methodology, guidelines of (Shanock, Baran, Gentry, Pattison, \& Heggestad, 2010) were followed.

\subsection{PLS Analysis}

The Smart-PLS software was used to do the PLS analysis. To test the overall fit of the proposed research models (Figure 1), we conducted a confirmatory composite analysis by following the guidelines (Henseler et al., 2014) and (Benitez, Henseler, \& Castillo, 2017). The models were tested using ADANCO 2.0.1 software (Dijkstra \& Henseler, 2015), with the bootstrap resampling method (4,999 resamples). It followed the guidelines of (Dijkstra, 2010), and subconstructs were estimated by using the regression weights (mode B). Therein, we observed the standardised root mean squared residual (SRMR), unweighted least squares (ULS) discrepancy (dULS), and geodesic discrepancy (dG), which let us assess the appropriateness of the composite model. The SRMR of the a-priori model was 0.033 for the control group (Study-1) and 0.041 for the experimental group (Study-2)- well below the recommended threshold of less than 0.080 - at the 0.05 alpha level (Dijkstra \& Henseler, 2015; Hu \& Bentler, 1999). The dULS $=0.103$ and $\mathrm{dG}=0.017$ for the control group indicated that we could confirm with a probability of $5 \%$ that the measurement structure of our proposed model was correct, demonstrating good model fit (Dijkstra \& Henseler, 2015; Hu \& Bentler, 1999).

Next, we established construct validity using the average variance extracted (AVE). Therein, we observed that for each construct the AVE was greater than the variance shared between the construct and the other constructs in the model, thus indicating strong construct and discriminant validity. Moreover, the strong and significant path coefficients for both pricing and awareness were shown (Study-1 for pricing was (0.401) and Study-2 (0.522), and the path coefficients of awareness for Study- 1 was 0.376 and for Study-2 it was 0.608). Finally, the R2 was determined for Study-1 and Study-2, revealing 0.22 and 0.31 respectively for Study- 1 and 2. The results confirm the overarching theoretical foundations (Figure 1), encouraging further investigation into the associations with pricing, awareness, and internet usage.

\subsection{Multi-Group Analysis}

A multi-group analysis permits to test whether the pre-defined subpopulations generate significant heterogeneous observations (Henseler, 2007). Therein, it tests the moderating effect of the subpopulations on the relationship between the observed independent and dependent variables (Henseler \& Chin, 2010; Henseler, Ringle, \& Sinkovics, 2009). The multi-group analysis commenced with the MICOM (measurement invariance of composite models) procedure, which assessed the invariance (Henseler, Ringle, \& Sarstedt, 2016). Henseler et al. (2016) recommend the use of MICOM, employing a three-step approach to analyse (i) configural invariance, (ii) compositional invariance, and (iii) the equality of composite mean values and variances. The results confirmed the three types of invariance, which implied that measurement invariance holds, and that a multi-group analysis is therefore possible (Hair et al., 2018; Henseler et al., 2016; Schlagel \& Sarstedt, 2016). Meaning that the moderating variable has no effect on the loadings of the elements in the model. After confirming the existence of invariance, the next step was to apply the multi-group analysis, comparing the explained 
variance for each group using appropriate categorical variables. In this case, age and gender analyses were carried out to identify if they create any impact. The last step of the multi-group analysis is to analyse the differences between coefficients in different paths. If these differences are significant (if the $\mathrm{p}$-value is smaller than 0.05 or larger than 0.95 for the difference of groupspecific path coefficients (see (Henseler et al., 2009))), the categorical variable has a moderating effect.

The age variable was divided into two subpopulations: below 25 years and above 25 years. Researchers suggest that younger persons are more environmentally perturbed than people of older age because environmentalism is a channel that shows younger persons' comparatively low contribution to the social order and the dominant value system (Abdul-Wahab \& Abdo, 2010; Arcury \& Christianson, 1993; Bell, Greene, Fisher, \& Baum, 1996). However, some literature suggests that environmental awareness grows with age as people get more mature and exposed to knowledge (Aminrad, Zakaria, \& Hadi, 2011; Ziadat, 2010). Nevertheless, the MGA showed no significant differences between the age groups. Further, past studies suggest that age also affects price sensitivity (Chaloupka \& Grossman, 1996). Younger a person, their disposable income is comparatively lower than those of higher age brackets, indicating that they are more sensitive towards price changes (Chaloupka \& Grossman, 1996; Ding, 2003; Hollingworth et al., 2006). However, price sensitivity might affect comparatively less on younger aged groups, if they are dependent on their parent's or guardian's income or if they are conscious of certain brands or products (Muratore, 2016). The two age groups depicted no differences in the analysis for the price (see Table 2).

\begin{tabular}{|l|l|l|l|l|l|l|}
\hline & $\begin{array}{l}\text { Group 1 } \\
\text { Age }=<25 \\
=75\end{array}$ & $\begin{array}{l}\text { Group 2 } \\
\text { Age }>25 \\
=251\end{array}$ & \multicolumn{3}{|c|}{ Group 1 vs. Group 2 } \\
\hline & $\beta$ Age $=<25$ & $\beta$ Age $>25$ & $\begin{array}{l}\text { I }\left(\beta_{\text {Age }=<25}-\right. \\
\left.\beta_{\text {Age }>25}\right)\end{array}$ & $\begin{array}{l}\text { t- } \\
\text { value }\end{array}$ & Significance & $p$-value \\
\hline $\begin{array}{l}\text { Price Affordability }>> \\
\text { Internet Usage }\end{array}$ & 0.571 & 0.518 & 0.053 & .863 & $\begin{array}{l}\text { Not } \\
\text { Significant }\end{array}$ & 0.471 \\
\hline $\begin{array}{l}\text { Env: Awareness } \\
>\text { Internet Usage }\end{array}$ & 0.489 & 0.416 & 0.073 & .881 & $\begin{array}{l}\text { Not } \\
\text { Significant }\end{array}$ & 0.437 \\
\hline
\end{tabular}

Table 2. Multi-group analysis of sub-samples based on age

These results could be due to the high literacy rate prevailing in Sri Lanka, where even younger persons have the maturity to grasp awareness, and on the other hand due to cheaper data prices of Sri Lanka. Results of the MGA depicted in Table 2 demonstrate that there were no significant differences between the age groups for both relationships.

Gender is another factor that we considered in the MGA. The literature proposes that males are more aware of environmental damage and engage in more pro-environmental behaviours than females because of their comparatively high engagement in the community and political issues (Abdul-Wahab \& Abdo, 2010; McEvoy, 1972).

In the notion of price sensitivity, the literature also suggests that males are more price sensitive, and hence more responsive to price changes than females (Andreoni \& Vesterlund, 2001). Results of the MGA based on gender revealed significant differences in how price affordability and environmental awareness affected their respective internet use. It is observed (See Table 
3) that men were more sensitive to both price affordability and environmental awareness showing an impact on their internet use, as compared to our female sample.

\begin{tabular}{|c|c|c|c|c|c|c|}
\hline & Group 1 & Group 2 & \multicolumn{4}{|c|}{ Group 1 vs. Group 2} \\
\hline & $\beta$ Male $=190$ & $\beta$ Female = 136 & $\begin{array}{l}\mid(\beta \text { Male = } 190 \\
-\beta \text { Female }= \\
136) \mid\end{array}$ & $\begin{array}{l}\text { t- } \\
\text { value }\end{array}$ & Significance & p-value \\
\hline $\begin{array}{l}\text { Price Affordability } \\
\text { >> Internet Usage }\end{array}$ & 0.613 & 0.586 & 0.027 & 3.744 & Significant & 0.001 \\
\hline $\begin{array}{l}\text { Env: Awareness >> } \\
\text { Internet Usage }\end{array}$ & 0.629 & 0.515 & 0.114 & 5.193 & Significant & 0.001 \\
\hline
\end{tabular}

Table 3. Multi-group analysis of sub-samples based on gender

In the notion of price sensitivity, the literature also suggests that males are more price sensitive, and hence more responsive to price changes than females (Andreoni \& Vesterlund, 2001). Results of the MGA based on gender revealed significant differences in how price affordability and environmental awareness affected their respective internet use. It is observed (See Table 3) that men were more sensitive to both price affordability and environmental awareness showing an impact on their internet use, as compared to our female sample

\subsection{Polynomial Regression}

Polynomial regression is a technique to model the relationship between multiple independent variables (X and $\mathrm{Y}$ ) concerning a dependent variable $(\mathrm{Z})$ through a non-linear relationship (Shanock et al., 2010). Similar to polynomial regression (Edwards \& Parry, 1993), response surface methodology - abbreviated as 'PR and RSM' - (Box \& Draper, 1987; Cornell \& Khuri, 1987 ) is a common technique that analyses non-linearities. PR and RSM allow researchers to examine the extent to which the combinations of two predictor (independent) variables relate to an outcome (dependent) variable.

According to Venkatesh and Goyal (2010), linear models do not bring out the theory projected complications appropriately. The PR and RSM are ideal to investigate the purported relationship between price and awareness and its hypothesised relationship with the internet use of the consumer. As such, we labelled price as $\mathrm{X}$ variable, awareness as the $\mathrm{Y}$ variable, whilst internet use was labeled as the outcome variable $Z$, where the equation was,

1. Internet use $=f\left(\right.$ price $^{*}$, awareness $\left.{ }^{* *}\right)$

The complete empirical specification was:

2. Internet use $=\beta 0+\beta 1$ Price $^{*}+\beta 2$ Awareness $^{* *}+\beta 3$ Price $2+\beta 4$ (Price $x$ Awareness) $+\beta 5$ Awareness2 +e

We followed the procedure outlined in (Shanock et al., 2010) to run the polynomial regression analysis on the data collected from 326 consumers to create the response surface as shown in Figure 3. Panel (a) of Figure 3 represents the data of Study-1 and panel (b) of Figure 3represents data of Study-2. 


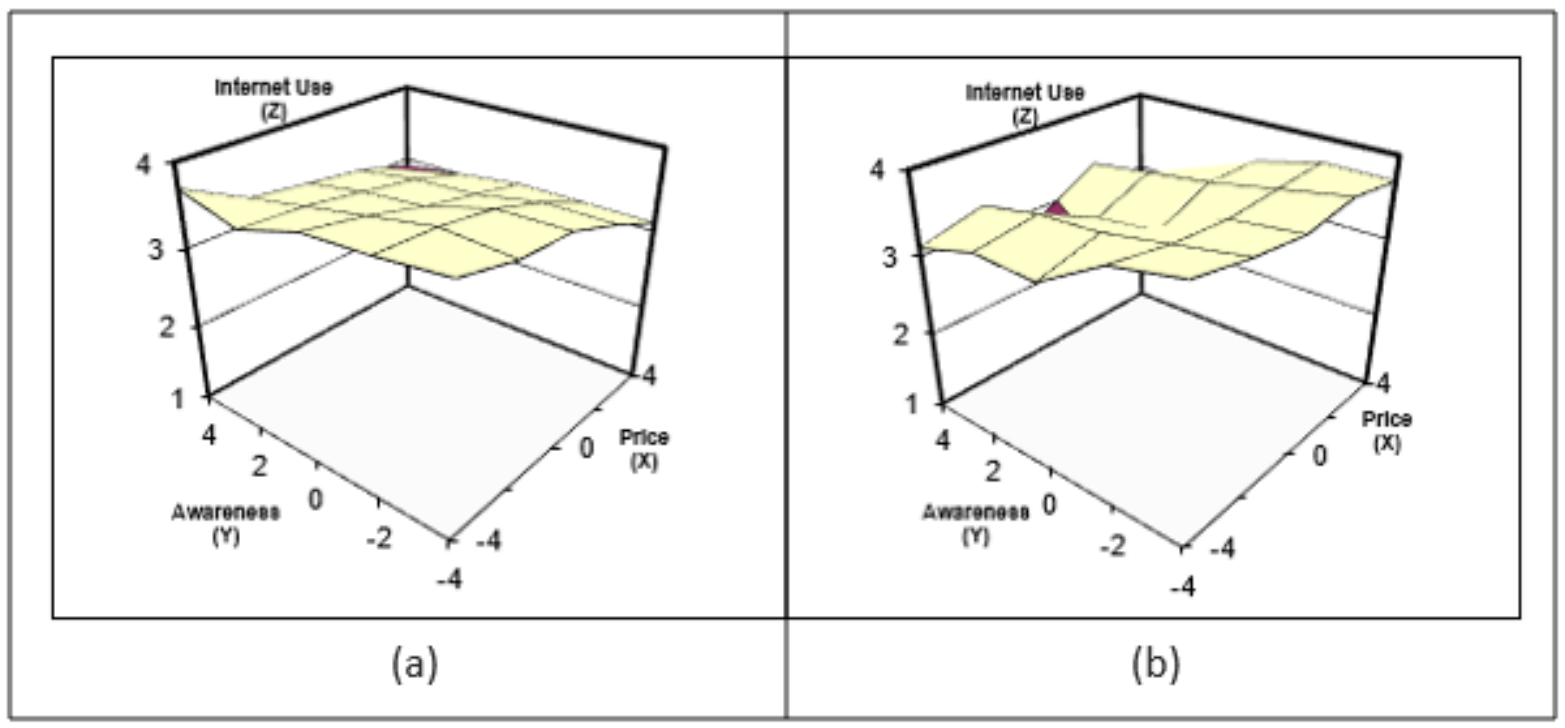

Figure 3. Response Surfaces of Study-1 and Study-2

According to Table 4, a significant a1 indicated that the line of the agreement had an additive relationship to the outcome variable. A positive a1 indicated that the outcome

\begin{tabular}{|l|l|l|l|l|l|}
\hline \multirow{2}{*}{ Effect } & Study Phase & Coefficient & Std error & Test stat (t) & Significance \\
\hline \multirow{2}{*}{$\begin{array}{l}\text { a1: Slope along X=Y (as } \\
\text { related to Z) }\end{array}$} & Study-1 & -0.21 & 0.09 & -9.226 & Significant \\
\cline { 2 - 6 } & Study-2 & -0.47 & 0.03 & -12.988 & Significant \\
\hline \multirow{2}{*}{$\begin{array}{l}\text { a2: Curvature on X=Y } \\
\text { (as related to Z) }\end{array}$} & Study-1 & -0.48 & 0.02 & -12.014 & Significant \\
\cline { 2 - 6 } & Study-2 & 0.34 & 0.03 & 5.534 & Significant \\
\hline \multirow{2}{*}{$\begin{array}{l}\text { a3: Slope along X=-Y (as } \\
\text { related to Z) }\end{array}$} & Study-1 & 0.15 & 0.06 & 7.13 & Significant \\
\cline { 2 - 6 } & Study-2 & 0.07 & 0.02 & 0.73 & Non-significant \\
\hline $\begin{array}{l}\text { a4: Curvature on X=-Y } \\
\text { (as related to Z) }\end{array}$ & Study-1 & 0.09 & 0.18 & 1.11 & Non-Significant \\
\cline { 2 - 6 } & Study-2 & -0.31 & 0.73 & -11.682 & Significant \\
\hline
\end{tabular}

Table 4. Longitudinal Assessment of Study 1 and Study 2

variable increased as both predictor variables increased, whereas a negative a1 indicated that the outcome variable decreased as both predictor variables increased. A significant a2 for Study-1 indicated a non-linear slope of the line of perfect agreement (agreement in the two predictor variables related to the outcome in a nonlinear way) (Shanock et al., 2010). The significant and negative values of a2 in Study-1 suggested that the line of perfect agreement as it relates to internet use was positive and a convex surface (upward curving). For Study-2 we observed a concave surface with downward curving. Next, we interpret how the degree of discrepancy between price and awareness relates to the outcome variable internet usage, by assessing the curvature along the line of incongruence $(X=-Y)$ as it relates to internet usage with a4. We observed, significant negative a4 for Study-2, and non-significant for the data of Study-1 showed a slight concave surface (See Figure 3), that is, internet use would increase slightly as the degree of discrepancy between breadth and depth decreases. Finally, we considered a3 to establish the direction of the discrepancy related to the outcome, as indicated by the slope of the $X=-Y$ line (line of incongruence) as it relates to internet usage. A significant negative a3 for Study-2 (see Table 4) indicated that internet usage was higher when the discrepancy was such that price was higher than awareness and vice versa. 


\section{Application of the Framework}

Encouraged by the polynomial regression results and consistent with the notions presented in the literature review, we see a continuum of internet user behaviours relating to the combined effects of internet pricing and environmental awareness. Figure 4 presents four types of internet user behaviours, arranged in a $2 \times 2$ matrix associated with price and awareness. The framework is intended as a practical tool to guide future directions in relation to this research. Therein, we created four possible self-explanatory behaviour types: opportunistic, idealistic, tautological, and prohibitive - each representing an internet use category for the four 'highlow' combinations of awareness and price.

In Figure 4, the position where price and awareness are low is termed as 'opportunistic'. It indicates that the consumer engages in maximising his utility by exploiting the resources (Watts \& Zimmerman, 1978). Our analysis showed it as the category that represents the highest intention to use the internet, asserting to the characteristics found in the literature of exploitive usage of resources. Rivera and De Leon (2004) in their study show that ski-riding for free and lack of monitoring has made riders exploit the resources. These instances show that when there are fewer restrictions people tend to exploit resources for their advantage. Similarly, the behavioural intention identified through internet consumers in Study- 1 is consistent with the opportunistic assumptions. However, in Study-2, even after inducing awareness, the opportunistic behaviour of consumers remains as it is. This implies that for behavioural changes of opportunistic consumers inducing awareness will not create any changes in personal values and attitudes when the price remains low.

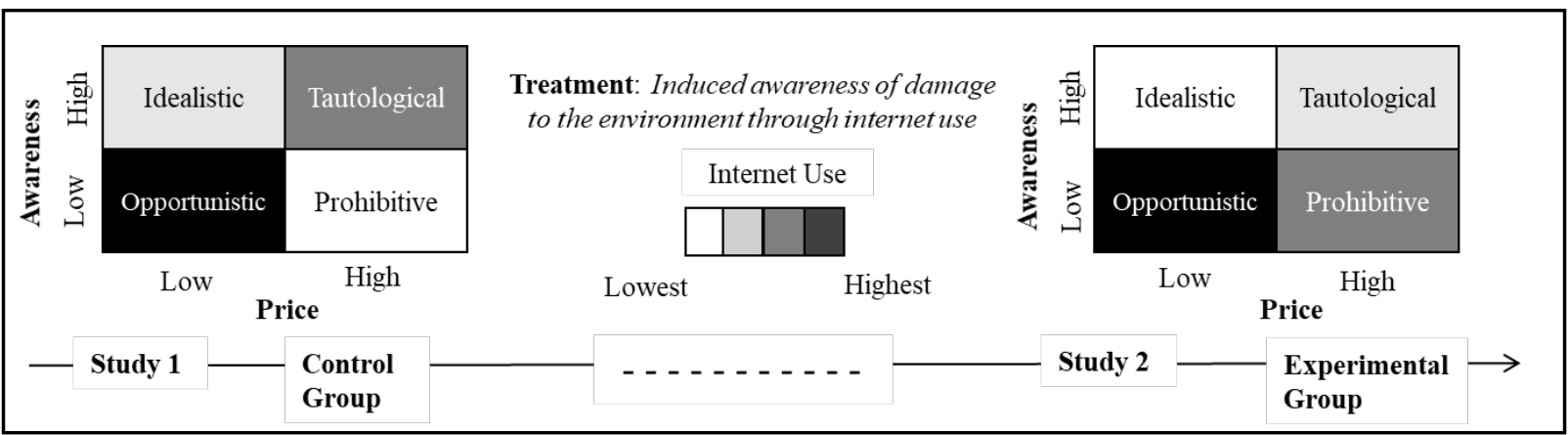

Figure 4. The application framework that summarises findings using a $2 \times 2$ matrix of price and awareness on internet usage

The combination of high-awareness and low-price in Figure 4 is denoted as 'idealistic'. Idealism is recognised as behaviour that emerges when principles and values acquire a major proportion in an individual's cognition than existing practical conditions (Kivetz \& Tyler, 2007). In a pro-environmental context, this can be interpreted as being environmentally and socially responsible (Kivetz \& Tyler, 2007). Agreeing to reduce internet consumption due to high awareness of the damage even when the prices are low is assumed as the idealistic behaviour in our study. The literature suggests that awareness programs like anti-alcohol and road safety campaigns have resulted in a reduction of destructive and unhealthy behaviour even when there are no other benefits to the consumer, confirming the idealistic behaviour (Nemtsov, 1998; Rundmo \& Iversen, 2004). Replicating the same characteristics, in the combination of low-price and high-awareness, our study showed the idealistic behaviour 
pattern in Study-2. It elucidates that, after the inducement of awareness users tend to restrict their usage even more because awareness has created a substantial impact on the consumer.

Next, we define the combination of high-price and high-awareness in Figure 4 as 'tautological', logically indicating that internet usage should be the lowest as of the tautological assumptions. Tautology as explained by Priem and Butler (2001) is a statement that is always logically true to the prepositional interpretations. Aligning to the tautological assumptions, the intention of internet consumption decreased in Study-2 after inducing awareness. Previous studies on cigarette consumption also show similar behaviour where tax-induced pricing and awareness campaigns reduced cigarette consumption (Cantrell et al., 2013). Therefore, we can assume that awareness has a notable impact on the intention to use the internet in the tautological consumer category.

As the last combination, we term the high-price and low-awareness pair as 'prohibitive.' Although awareness is less, external prohibitive factors such as high price discourage intention to use the internet, according to the characteristics of prohibitive behaviour in previous studies (Liang et al., 2012; Lin \& Johnson, 2015). Study-1 perfectly brings out this phenomenon in which the prohibitive category showed the lowest intention to use the internet. Since only price has played the prohibitive role in Study-1, the impact of awareness has become unimportant there. However, according to Study-2, the effect of the prohibitive factor does not create such an effect as the intention to consume the internet increases. Our observations highlight the complexity of human behaviour, where the intended behaviour deviates from the accepted 'prohibitive' assumptions.

Overall, it is clear that 'prohibitive' (high price - low awareness) is the most effective combined strategy, before increasing environmental awareness (Study-1), while 'idealistic' behaviour marks the lowest point of internet use (low price - high awareness) after awareness.

\section{Summary}

The purpose of conducting this study was to examine the effect of pricing and awareness of environmental damage, on the internet usage of individuals. As per the results of the analysis of 326 respondents, a statistically significant relationship was observed between pricing and awareness with internet use.

The following main findings were extracted from the analysis. Three observations were made for Study-1 (before inducing awareness): (i) internet usage was highest, where both price and awareness were at their lowest. (ii) internet use was at the lowest when the price was at the highest and the awareness was at the lowest. (iii) the impact of awareness was insignificant, with price increases. However, after inducing awareness (Study-2), the following three observations were made: (iv) internet usage was at the lowest, when awareness was the highest, with the lowest price, (v) internet usage remained low (though not the lowest) for high awareness, even when the price increases, (vi) price diminished its significance on usage, with increasing awareness.

Moreover, the results parallel with other contexts that have used pricing and awareness as strategies to control human behaviour. The study outcomes show that awareness creates a significant impact on reducing internet usage. Moreover, the price creates a significant impact on internet usage. Finally, the moderating effect of pricing on the relationship between awareness and internet usage also shows significant results. However, it should be noted that 
the impact awareness alone creates is higher than the impact both pricing alone creates, and pricing and awareness together create on internet usage.

The MGA of age and gender on the relationships between price affordability and awareness on internet usage reveals interesting results. The study shows that the two age groups (above and below 25 years), did not yield any significant differences in the relationships observed. That means, they did not indicate any significant moderating effect on the relationship between environmental awareness and internet usage, or price affordability and internet usage. However, the gender variable indicated differences in the relationships observed where males were more sensitive to both price and awareness than the female sample. That means, the observed relationships were moderated by the variable gender.

Our study contributes to the VBN theory by observing a causal relationship that entails 'personal financial capabilities,' 'general environmentalist predispositions' and 'change in lifestyle.' On one hand, it showed that the impact of awareness was nonsignificant with the increase in price before inducing awareness. That is, before inducing awareness, the egoistic values of a person generated beliefs like ecological world view, awareness of consequences, and ascription of responsibility. As a result, personal norms activated, and according to an individual's norms, he altered his intention to behave. On the other hand, the study showed that with the increase of awareness, the significance of price on behavioural intention reduced. That is, after inducing awareness, biospheric and altruistic values of consumers generated, and it led to the generation of beliefs, personal norms, and finally the intention to behave. The polynomial hypothesis of the co-existence of such factors makes the study findings closer to reality.

Figure 4 provided a practical framework to understand the continuum of internet use behaviours. The classification can be used to identify how behaviour patterns of individuals change when awareness and price change. Accordingly, it can be used to decide which and when to employ the strategies to reduce internet consumption. If awareness strategies that increase motivation to reduce internet usage are not employed, then an increase in internet service prices that creates prohibitive behaviours can be introduced as the best option. However, idealistic behaviours that reduce internet usage significantly, can be observed when awareness is increased which manipulates people's values, principles, and attitudes. Henceforth, after inducing awareness, internet price can be decreased.

This research was tested using data only from Sri Lanka which would restrict to gain an overall global picture of the changes in internet usage in manipulating independent variables. Therefore, we encourage further validation of results by gathering data from other countries that have different internet infrastructure and cultural values. Furthermore, the study measures general internet usage of individuals which cannot be reduced at times based on the user's purpose of using the internet (e.g.: sending a work email). Therein, we identify that changes individuals do to their internet usage depend on the need of the user, and the study does not specifically investigate internet usage based on the purpose of the user. We encourage the study of internet use based on specific purposes such as internet use for leisure and work. Moreover, we have considered internet use in only block-rate pricing strategy, which is the most popular pricing strategy in Sri Lanka. Results are true to the studied pricing structure. However, we recognise that some countries provide unlimited internet data through fixed pricing. Therefore, further generalisability is planned through extended studies of all pricing models. Moreover, we gathered data during a global pandemic that may have augmented 
internet use across the globe. As such, future studies must consider the possible adverse effect that such high use may have added to the study findings. Further, the consumer's willingness to pay premium pricing and its effect on consumers' intention to use the internet could be tested through a future study. Premium pricing is the price that a customer is willing to pay extra for the environment for the same usage of the internet. Premium pricing associates with uniqueness and quality as well as emotional engagement, and hence, a consumer might tend to pay more if they feel satisfied or contributed towards environmental wellbeing. This phenomenon can be tested with the inducement of environmental awareness. Moreover, as another future implication, more inclusive measurements of additional VBN variables can be used to test how the intentions of consumers change. For that, variables like altruistic feelings towards nature, governmental policies, the maturity level of consumers can be tested in seeking the expected output.

\section{References}

Abdul-Wahab, S. A., \& Abdo, J. (2010). The effects of demographic factors on the environmental awareness of Omani citizens. Human and ecological risk assessment: An International Journal, 16(2), 380-401. doi:https://doi.org/10.1080/10807031003670410

Abrahamse, W., \& Steg, L. (2011). Factors related to household energy use and intention to reduce it: The role of psychological and socio-demographic variables. Human ecology review, 18(1), 30-40. doi:http://www.jstor.org/stable/24707684

Aebli, A., Volgger, M., \& Taplin, R. (2021). A two-dimensional approach to travel motivation in the context of the COVID-19 pandemic. Current Issues in Tourism, 1-16. doi:https://doi.org/10.1080/13683500.2021.1906631

Aengenheyster, M., Feng, Q. Y., Van Der Ploeg, F., \& Dijkstra, H. A. (2018). The point of no return for climate action. Earth System Dynamics, 9(3), 1085-1095. doi:https://doi.org/10.5194/esd-9-1085-2018

Aldossary, M., \& Djemame, K. (2016, September). Energy consumption-based pricing model for cloud computing. Paper presented at the 32nd UK Performance Engineering Workshop, University of Bradford, UK. Retrieved January 20, 2020, from http://eprints.whiterose.ac.uk/104975/

Aldossary, M., Djemame, K., Alzamil, I., Kostopoulos, A., Dimakis, A., \& Agiatzidou, E. (2019). Energy-aware cost prediction and pricing of virtual machines in cloud computing environments. Future Generation Computer Systems, 93, 442-459. doi:https://doi.org/10.1016/j.future.2018.10.027

Alford, B. L., \& Biswas, A. (2002). The effects of discount level, price consciousness and sale proneness on consumers' price perception and behavioral intention. Journal of Business Research, 55(9), 775-783. doi:https://doi.org/10.1016/S0148-2963(00)00214-9

Aminrad, Z., Zakaria, S., \& Hadi, A. S. (2011). Influence of age and level of education on environmental awareness and attitude: case study on Iranian students in Malaysian Universities. The Social Sciences, 6(1), 15-19. doi:10.3923/sscience.2011.15.19

Andrae, A., \& Edler, T. (2015). On Global Electricity Usage of Communication Technology: Trends to 2030. Challenges, 6(1), 117-157. doi:10.3390/challe6010117

Arcury, T. A., \& Christianson, E. H. (1993). Rural-urban differences in environmental knowledge and actions. The Journal of Environmental Education, 25(1), 19-25. doi:10.1080/00958964.1993.9941940 
Arlt, D., Hoppe, I., \& Wolling, J. (2011). Climate change and media usage: Effects on problem awareness and behavioural intentions. International Communication Gazette, 73(1-2), $45-$ 63. doi:https://doi.org/10.1177/1748048510386741

Atwater, L., Waldman, D., Ostroff, C., Robie, C., \& Johnson, K. M. (2005). Self-other agreement: Comparing its relationship with performance in the US and Europe. International Journal of Selection and Assessment, 13(1), 25-40. doi:https://doi.org/10.1111/j.0965075X.2005.00297.x

Ball, K., McNaughton, S. A., Mhurchu, C. N., Andrianopoulos, N., Inglis, V., McNeilly, B., Le, H. N., Leslie, D., Pollard, C., \& Crawford, D. (2011). Supermarket Healthy Eating for Life (SHELf): protocol of a randomised controlled trial promoting healthy food and beverage consumption through price reduction and skill-building strategies. BioMed Central Public Health, 11(1), 715. doi:https://doi.org/10.1186/1471-2458-11-715

Bateni, M. H., Hajiaghayi, M. T., Jafarpour, S., \& Pei, D. (2011, April). Towards an efficient algorithmic framework for pricing cellular data service. Paper presented at the IEEE International Conference on Computer Communications, Shanghai, China. Retrieved February 20, 2020, from https://ieeexplore.ieee.org/document/5935231

Bell, P. A., Greene, T. C., Fisher, J. D., \& Baum, A. (1996). Environmental psychology. New York: Harcourt Brace.

Benitez-Amado, J., Henseler, J., \& Castillo, A. (2017, July). Development and update of guidelines to perform and report partial least squares path modeling in Information Systems research. Paper presented at the 21st Pacific Asia Conference on Information Systems, Langkawi, Malaysia. Retrieved March 02, 2020, from https://core.ac.uk/download/pdf/301372855.pdf

Benitez-Amado, J., Llorens-Montes, F. J., \& Fernandez-Perez, V. (2013, August). The relationship between IT infrastructure leveraging, talent management and operational sustainability, and their effects on the business value of the operations strategy. Paper presented at the Americas Conference on Information Systems, Chicago, Illinois. Retrieved from March 02, 2020 from https://core.ac.uk/download/pdf/301359353.pdf

Box, G. E., \& Draper, N. R. (1987). Empirical Model-Building and Response Surfaces. New York: John Wiley \& Sons.

Brewer, N. T., Hall, M. G., Noar, S. M., Parada, H., Stein-Seroussi, A., Bach, L. E., Hanley, S., \& Ribisl, K. M. (2016). Effect of pictorial cigarette pack warnings on changes in smoking behavior: a randomized clinical trial. The Journal of the American Medical Association Internal Medicine, 176(7), 905-912. 10.1001/jamainternmed.2016.2621

Briscar, J. R. (2017). Data Transmission and Energy Efficient Internet Data Centers. American University Law Review, 67(1), 233-268

Brounen, D., Kok, N., \& Quigley, J. M. (2013). Energy literacy, awareness, and conservation behavior of residential households. Energy Economics, 38, 42-50. doi:https://doi.org/10.1016/j.eneco.2013.02.008

Bulgurcu, B., Cavusoglu, H., \& Benbasat, I. (2010). Information security policy compliance: an empirical study of rationality-based beliefs and information security awareness. Management Information Systems Quarterly, 34(3), 523-548. doi:10.2307/25750690

Cantrell, J., Kreslake, J. M., Ganz, O., Pearson, J. L., Vallone, D., Anesetti-Rothermel, A., Xiao, H., \& Kirchner, T. R. (2013). Marketing little cigars and cigarillos: advertising, price, and associations with neighborhood demographics. American Journal of Public Health, 103(10), 1902-1909. doi:10.2105/AJPH.2013.301362 
Chaloupka, F. J., \& Grossman, M. (1996). Price, tobacco control policies and youth smoking. National Bureau of Economic Research (Working Paper No. 5740). doi:10.3386/w5740

Chen, H., Hui, H., Su, Z., Fang, D., \& Hui, Y. (2017). Real-Time Pricing Strategy Based on the Stability of Smart Grid for Green Internet of Things. Mobile Information Systems, 2017, 111. doi:https://doi.org/10.1155/2017/5039702

Chen, T., Sze, N., Saxena, S., Pinjari, A. R., Bhat, C. R., \& Bai, L. (2020). Evaluation of penalty and enforcement strategies to combat speeding offences among professional drivers: a Hong Kong stated preference experiment. Accident Analysis E Prevention, 135, 105-366. doi:https://doi.org/10.1016/j.aap.2019.105366

Chi, X., Hong, X., \& Chen, X. (2020). Profiles and sociodemographic correlates of Internet addiction in early adolescents in southern China. Addictive Behaviors, 106, 106-385. doi:https://doi.org/10.1016/j.addbeh.2020.106385

Clement, J. (2019). Global digital population as of October 2019. Retrieved March 05, 2020, from https://www.statista.com/statistics/617136/digital-population-worldwide/

Clement, J. (2020). Age distribution of internet users worldwide 2019. Retrieved March 05,2020, from https://www.statista.com/statistics/272365/age-distribution-of-internetusers-worldwide/

Cooper, V. A., \& Molla, A. (2014). Absorptive capacity and contextual factors that influence green IT assimilation. Australasian Journal of Information Systems, 18(3), 271-288. doi:https://doi.org/10.3127/ajis.v18i3.1099

Cornell, J. A., \& Khuri, A. I. (1987). Response surfaces: designs and analyses. New York: Marcel Dekker, Inc.

Curry, S. J., Wagner, E. H., \& Grothaus, L. C. (1991). Evaluation of intrinsic and extrinsic motivation interventions with a self-help smoking cessation program. Journal of consulting and clinical psychology, 59(2), 318. doi:https://doi.org/10.1037/0022006X.59.2.318

De Vries, H., Mudde, A., Leijs, I., Charlton, A., Vartiainen, E., Buijs, G., Clemente, M. P., Storm, H., Navarro, A. G., \& Nebot, M. (2003). The European Smoking prevention Framework Approach (EFSA): an example of integral prevention. Health Education Research, 18(5), 611-626. doi:https://doi.org/10.1093/her/cyg031

Delhaye, E. (2007). The enforcement of speeding: Should fines be higher for repeated offences? Transportation planning and technology, 30(4), 355-375. doi:https://doi.org/10.1080/ 03081060701461758

Dijkstra, T. K. (2010). Latent variables and indices: Herman Wold's basic design and partial least squares. In Handbook of Partial Least Squares (pp. 23-46). Berlin, Heidelberg: Springer.

Dijkstra, T. K., \& Henseler, J. (2015). Consistent partial least squares path modeling. Management Information Systems Quarterly, 39(2), 297-316. doi:https://www.jstor.org/ stable/26628355

Ding, A. (2003). Youth are more sensitive to price changes in cigarettes than adults. The Yale Journal of Biology and Medicine, 76(3), 115-124.

Ebbs, D., Dahlhaus, P., Barton, A., \& Kandra, H. (2018). An unexpected decrease in urban water demand: making discoveries possible by taking a long-term view. Water Policy, 20(3), 617-630. doi:https://doi.org/10.2166/wp.2018.096

Edwards, J. R., \& Parry, M. E. (1993). On the use of polynomial regression equations as an alternative to difference scores in organizational research. Academy of Management Journal, 36(6), 1577-1613. doi:https://doi.org/10.5465/256822 
Elliot, S., \& Binney, D. (2008). Environmentally sustainable ICT: Developing corporate capabilities and an industry-relevant IS research agenda. Paper presented at the Pacific Asia Conference in Information Systems, Suzhou, China. Retrieved March 01, 2020, from https://aisel.aisnet.org/cgi/viewcontent.cgi?article=1239\&context=pacis2008

Eriksson, L., Garvill, J., \& Nordlund, A. M. (2006). Acceptability of travel demand management measures: The importance of problem awareness, personal norm, freedom, and fairness. $\begin{array}{llll}\text { Journal of Environmental Psychology, 26(1), 15-26. } & \end{array}$ doi:https://doi.org/10.1016/j.jenvp.2006.05.003

Fan, Q. (2005). Regulatory factors influencing Internet access in Australia and China: a comparative analysis. Telecommunications Policy, 29(2-3), 191-203. doi:https://doi.org/10.1016/j.telpol.2004.11.007

Farrelly, M. C., Duke, J. C., Nonnemaker, J., MacMonegle, A. J., Alexander, T. N., Zhao, X., Delahanty, J. C., Rao, P., \& Allen, J. A. (2017). Association between The Real Cost media campaign and smoking initiation among youths-United States, 2014-2016. 66(2), 47-50. Retrieved from https://www.ncbi.nlm.nih.gov/pmc/articles/PMC5657653/

Ferrer, R. A., Orehek, E., Scheier, M. F., \& O'Connell, M. E. (2018). Cigarette tax rates, behavioral disengagement, and quit ratios among daily smokers. Journal of Economic Psychology, 66, 13-21. doi:https://doi.org/10.1016/j.joep.2018.03.005

France24 (Producer). (2017). The hidden pollution of the internet. Retrieved from https://www.youtube.com/watch? $\mathrm{v}=\mathrm{GX} 8 \mathrm{sOrz}$-Fg\&t=18s

Fricker, R. D. (2008). Sampling methods for web and e-mail surveys. In The SAGE Handbook of Online Research Methods (pp. 195-216). London: SAGE Publications Ltd.

Frieden, T. R., Mostashari, F., Kerker, B. D., Miller, N., Hajat, A., \& Frankel, M. (2005). Adult tobacco use levels after intensive tobacco control measures: New York City, 2002-2003. American Journal of Public Health, 95(6), 1016-1023. doi:10.2105/AJPH.2004.058164

Ghansah, F. A., Owusu-Manu, D.-G., Ayarkwa, J., Edwards, D. J., \& Hosseini, M. R. (2021). Assessing the level of awareness of smart building technologies (SBTs) in the developing countries. Journal of Engineering, Design and Technology. doi:https://doi.org/10.1108/ JEDT-11-2020-0465

Giesbrecht, N., \& Greenfield, T. K. (2003). Preventing alcohol-related problems in the US through policy: Media campaigns, regulatory approaches and environmental interventions. Journal of Primary Prevention, 24(1), 63-104. doi:https://doi.org/10.1023/A:1025027701426

Goiri, Í., Katsak, W., Le, K., Nguyen, T. D., \& Bianchini, R. (2013). Parasol and greenswitch: Managing datacenters powered by renewable energy. Association for Computing Machinery Special Interest Group on Programming Languages Notices, 48(4), 51-64. doi:https://doi.org/10.1145/2499368.2451123

Google. (2019). Google Environmental Report. Retrieved January 08, 2020, from https://services.google.com/fh/files/misc/google_2019-environmental-report.pdf

Grishchenko, N. (2020). The gap not only closes: Resistance and reverse shifts in the digital divide in Russia. Telecommunications Policy, 44(8), 102004. doi:https://doi.org/ 10.1016/j.telpol.2020.102004

Hair, J. F., Ringle, C. M., Gudergan, S. P., Fischer, A., Nitzl, C., \& Menictas, C. (2018). Partial least squares structural equation modeling-based discrete choice modeling: an illustration in modeling retailer choice. Business Research. doi:10.1007/s40685-018-0072-4

Hallegatte, S. (2009). Strategies to adapt to an uncertain climate change. Global Environmental Change, 19(2), 240-247. doi:10.1016/j.gloenvcha.2008.12.003 
Haltinner, K., \& Sarathchandra, D. (2021). The Nature and Nuance of Climate Change Skepticism in the United States. Rural Sociology, 1-30. doi:https://doi.org/10.1111/ ruso. 12371

Han, T., Coles, H., Price, P. N., Gadgil, A., \& Tschudi, W. (2019). Corrosion coupons may not be useful for predicting data center equipment failure rates. Center of Expertise for Energy Efficiency in Datacenters, United States Department of Energy. Retrieved March 22, 2020, from https://libguides.scu.edu.au/apa6/government/statistical/technicalpublications

Haque, M. M., Ahmend, A., \& Rahman, A. (2013). Impacts of water price and restrictions on water demand: A case study for Australia. In Water Conservation: Practices, Challenges and Future Implications (pp. 127-145). New York: Nova Science Publishers.

Henriksen, L. (2012). Comprehensive tobacco marketing restrictions: promotion, packaging, price and place. Tobacco Control, 21(2), 147-153. doi:10.1136/tobaccocontrol-2011-050416

Henseler, J. (2007, September). A new and simple approach to multi-group analysis in partial least squares path modeling. Paper presented at the The 5th International Symposium on PLS and Related Methods, Oslo, Norway. Retrieved April 10, 2020, from https://repository.ubn.ru.nl/handle/2066/160875

Henseler, J., \& Chin, W. W. (2010). A comparison of approaches for the analysis of interaction effects between latent variables using partial least squares path modeling. Structural Equation Modeling, 17(1), 82-109. doi:https://doi.org/10.1080/10705510903439003

Henseler, J., Dijkstra, T. K., Sarstedt, M., Ringle, C. M., Diamantopoulos, A., Straub, D. W., Ketchen Jr, D. J., Hair, J. F., Hult, G. T. M., \& Calantone, R. J. (2014). Common beliefs and reality about PLS: Comments on Rönkkö and Evermann (2013). Organizational Research Methods, 17(2), 182-209. doi:https://doi.org/10.1177/1094428114526928

Henseler, J., Ringle, C. M., \& Sarstedt, M. (2016). Testing measurement invariance of composites using partial least squares. International Marketing Review, 33(3), 405-431. doi:https://doi.org/10.1108/IMR-09-2014-0304

Henseler, J., Ringle, C. M., \& Sinkovics, R. R. (2009). The use of partial least squares path modeling in international marketing. In R. R. Sinkovics \& P. N. Ghauri (Eds.), New Challenges to International Marketing (Vol. 20, pp. 277-319). Bingly: Emerald Group Publishing Limited.

Henseler, J., \& Sarstedt, M. (2013). Goodness-of-fit indices for partial least squares path modeling. Computational Statistics, 28(2), 565-580. doi:https://doi.org/10.1007/s00180-0120317-1

Hershey, J. C., Niederdeppe, J., Evans, W. D., Nonnemaker, J., Blahut, S., Holden, D., Messeri, P., \& Haviland, M. L. (2005). The theory of" truth": how counterindustry campaigns affect smoking behavior among teens. Health Psychology, 24(1), 22-31. doi:10.1037/02786133.24.1.22

Hill, J., Widdicks, K., \& Hazas, M. (2020, June). Mapping the Scope of Software Interventions for Moderate Internet Use on Mobile Devices. Paper presented at the 7th International Conference on ICT for Sustainability, Bristol, United Kingdom. Retrieved August 20, 2020, from https://dl.acm.org/doi/pdf/10.1145/3401335.3401361

Hobman, E. V., \& Frederiks, E. R. (2014). Barriers to green electricity subscription in Australia:"Love the environment, love renewable energy... but why should I pay more?". Energy Research \& Social Science, 3(1), 78-88. doi:https://doi.org/10.1016/j.erss.2014.07.009 
Hollingworth, W., Ebel, B. E., McCarty, C. A., Garrison, M. M., Christakis, D. A., \& Rivara, F. P. (2006). Prevention of deaths from harmful drinking in the United States: the potential effects of tax increases and advertising bans on young drinkers. Journal of Studies on Alcohol, 67(2), 300-308. doi:https://doi.org/10.15288/jsa.2006.67.300

Hu, L. t., \& Bentler, P. M. (1999). Cutoff criteria for fit indexes in covariance structure analysis: Conventional criteria versus new alternatives. Structural Equation Modeling: A Multidisciplinary Journal, 6(1), 1-55. doi:https://doi.org/10.1080/10705519909540118

IPCC. (2021). Summary for Policymakers. In V. Masson-Delmotte, P. Zhai, A. Piran, S. L. Connors, C. Péan, S. Berger, N. Caud, Y. Chen, L. Goldfarb, M. I. Gomis, M. Huang, K. Leitzell, E. Lonnoy, J. B. R. Matthews, T. K. Maycock, T. Waterfield, O. Yelekçi, R. Yu, \& B. Zhou (Eds.), Climate Change 2021: The Physical Science Basis. Contribution of Working Group I to the Sixth Assessment Report of the Intergovernmental Panel on Climate Change: Cambridge University Press. In Press. Retrieved September 05, 2020, from https://www.ipcc.ch/report/ar6/wg1/downloads/report/IPCC_AR6_WGI_Full_Report_ smaller.pdf

Islam, M., Saidur, R., Rahim, N., \& Solangi, K. (2010). Usage of solar energy and its status in Malaysia. Engineering e-Transaction, 5(1), 6-10.

ITU. (2019). The digital gender gap is growing fast in developing countries. Retrieved April 05, 2020, from https://itu.foleon.com/itu/measuring-digital-development/gender-gap/

ITU. (2020). Affordability. Retrieved November 20, 2020, from https://www.itu.int/en/ mediacentre/backgrounders/Pages/affordability.aspx

Izquierdo, F. A., Ramírez, B. A., McWilliams, J. M., \& Ayuso, J. P. (2011). The endurance of the effects of the penalty point system in Spain three years after. Main influencing factors. Accident Analysis \& Prevention, 43(3), 911-922. doi:https://doi.org/10.1016/ j.aap.2010.11.014

Jakovcevic, A., \& Steg, L. (2013). Sustainable transportation in Argentina: Values, beliefs, norms and car use reduction. Transportation Research Part F: Traffic Psychology and Behaviour, 20, 70-79. doi:https://doi.org/10.1016/j.trf.2013.05.005

Jenkin, T. A., McShane, L., \& Webster, J. (2011). Green information technologies and systems: Employees' perceptions of organizational practices. Business $\mathcal{E}$ Society, 50(2), 266-314. doi:https://doi.org/10.1177/0007650311398640

Jenkin, T. A., Webster, J., \& McShane, L. (2011). An agenda for 'Green' information technology and systems research. Information and Organization, 21(1), 17-40. doi:https://doi.org/10.1016/j.infoandorg.2010.09.003

Jylhä, K. M., Tam, K. P., \& Milfont, T. L. (2020). Acceptance of group-based dominance and climate change denial: A cross-cultural study in Hong Kong, New Zealand, and Sweden. Asian Journal of Social Psychology. doi:10.1111/ajsp.12444

Kemp, S. (2019). Digital Around The World In 2019. Retrieved Feburary 20, 2020, from https://www.juancmejia.com/wp-content/uploads/2019/03/Digital-2019-WeAreSocial-yHootSuite.pdf

Kenney, M., \& Zysman, J. (2020). COVID-19 and the increasing centrality and power of platforms in China, the US, and beyond. Management and Organization Review, 16(4), 747752. doi: https://doi.org/10.1017/mor.2020.48

Khalaj, A. H., Scherer, T., Siriwardana, J., \& Halgamuge, S. (2014, December). Increasing the thermal efficiency of an operational data center using cold aisle containment. Paper presented at the 7th International Conference on Information and Automation for Sustainability, Colombo, Sri Lanka. doi:10.1109/ICIAFS.2014.7069633 
Kivetz, Y., \& Tyler, T. R. (2007). Tomorrow I'll be me: The effect of time perspective on the activation of idealistic versus pragmatic selves. Organizational Behavior and Human Decision Processes, 102(2), 193-211. doi:https://doi.org/10.1016/j.obhdp.2006.07.002

Kollmuss, A., \& Agyeman, J. (2002). Mind the gap: why do people act environmentally and what are the barriers to pro-environmental behavior? Environmental education research, 8(3), 239-260. doi:https://doi.org/10.1080/13504620220145401

Kothari, C. R. (2004). Research Methodology: Methods and Techniques (2 ed.). New Delhi: New Age International.

Kuruzovich, J., Viswanathan, S., Agarwal, R., Gosain, S., \& Weitzman, S. (2008). Marketspace or marketplace? Online information search and channel outcomes in auto retailing. Information Systems Research, 19(2), 182-201. doi:https://doi.org/10.1287/isre.1070.0146

Kuss, D., Griffiths, M., Karila, L., \& Billieux, J. (2014). Internet addiction: A systematic review of epidemiological research for the last decade. Current Pharmaceutical Design, 20(25), 4026-4052.

Lawshe, C. H. (1975). A quantitative approach to content validity. Personnel psychology, 28(4), 563-575. doi:10.1111/j.1744-6570.1975.tb01393.x

Lee, Y. S., Han, D. H., Kim, S. M., \& Renshaw, P. F. (2013). Substance abuse precedes internet addiction. Addictive Behaviors, 38(4), 2022-2025. doi:https://doi.org/10.1016/ j.addbeh.2012.12.024

Lewis, I., Watson, B., \& White, K. M. (2008). An examination of message-relevant affect in road safety messages: Should road safety advertisements aim to make us feel good or bad? Transportation Research Part F: Traffic Psychology and Behaviour, 11(6), 403-417. doi:https://doi.org/10.1016/j.trf.2008.03.003

Li, C., Tang, J., Tang, H., \& Luo, Y. (2019). Collaborative cache allocation and task scheduling for data-intensive applications in edge computing environment. Future Generation Computer Systems, 95, 249-264. doi:https://doi.org/10.1016/j.future.2019.01.007

Liang, J., Farh, C. I., \& Farh, J.-L. (2012). Psychological antecedents of promotive and prohibitive voice: A two-wave examination. Academy of Management Journal, 55(1), 71-92. doi:https://doi.org/10.5465/amj.2010.0176

Lin, S. H., \& Johnson, R. E. (2015). A suggestion to improve a day keeps your depletion away: Examining promotive and prohibitive voice behaviors within a regulatory focus and ego depletion framework. Journal of Applied Psychology, 100(5), 1381-1397. doi:10.1037/ap10000018

Liobikienè, G., \& Poškus, M. S. (2019). The Importance of Environmental Knowledge for Private and Public Sphere Pro-Environmental Behavior: Modifying the Value-BeliefNorm Theory. Sustainability, 11(12), 3324. doi:https://doi.org/10.3390/su11123324

Liu, S. (2019). Global number of data centers 2015-2021. Retrieved January 28, 2020, from https://www.statista.com/statistics/500458/worldwide-datacenter-and-it-sites/

López-Mosquera, N., \& Sánchez, M. (2012). Theory of Planned Behavior and the Value-BeliefNorm Theory explaining willingness to pay for a suburban park. Journal of environmental management, 113, 251-262. doi:https://doi.org/10.1016/j.jenvman.2012.08.029

Luchs, M. G., \& Mooradian, T. A. (2011). Sex, Personality, and Sustainable Consumer Behaviour: Elucidating the Gender Effect. Journal of Consumer Policy, 35(1), 127-144. doi:10.1007/s10603-011-9179-0

Luís, S., Vauclair, C.-M., \& Lima, M. L. (2018). Raising awareness of climate change causes? Cross-national evidence for the normalization of societal risk perception of climate change. Environmental Science \& Policy, 80, 74-81. doi:https://doi.org/10.1016/ 
j.envsci.2017.11.015

Lv, Q., \& Rouskas, G. N. (2010). An economic model for pricing tiered network services. Annals of Telecommunications-annales des Télécommunications, 65(3-4), 147-161. doi:https://doi.org/10.1007/s12243-009-0149-3

Maibach, E. (1993). Social marketing for the environment: Using information campaigns to promote environmental awareness and behavior change. Health promotion international, 8(3), 209-224. doi:https://doi.org/10.1093/heapro/8.3.209

Mathwick, C., \& Rigdon, E. (2004). Play, flow, and the online search experience. Journal of Consumer Research, 31(2), 324-332. doi:https://doi.org/10.1086/422111

McEvoy, J. (1972). The American concern with the environment. In J. W. R. Burch, J. N. H. Cheek, \& L. Taylor (Eds.), Social Behavior, Natural Resources and the Environment (pp. 214236). New York: Harper and Row.

McGinty, E. E., Goldman, H. H., Pescosolido, B., \& Barry, C. L. (2015). Portraying mental illness and drug addiction as treatable health conditions: effects of a randomized experiment on stigma and discrimination. Social Science $\mathcal{E}$ Medicine, 126, 73-85. doi:https://doi.org/10.1016/j.socscimed.2014.12.010

McGinty, E. E., Webster, D. W., \& Barry, C. L. (2013). Effects of news media messages about mass shootings on attitudes toward persons with serious mental illness and public support for gun control policies. American Journal of Psychiatry, 170(5), 494-501. doi:https://doi.org/10.1176/appi.ajp.2013.13010014

McKenna, F. P. (2007). Do attitudes and intentions change across a speed awareness workshop? Paper presented at the Behavioural Research in Road Safety Seminar, London, United Kingdom. Retrieved March 20, 2020, from https://citeseerx.ist.psu.edu/viewdoc/ download?doi=10.1.1.514.1615\&rep=rep1\&type=pdf

Milne, J. E. (2014). Storms Ahead: Climate Change Adaptation Calls for Resilient Funding. Vermont Law Review, 39(4), 819-866.

Molla, A. (2013). Identifying IT sustainability performance drivers: Instrument development and validation. Information Systems Frontiers, 15(5), 705-723. doi:10.1007/s10796-013-9415$\mathrm{Z}$

Molla, A., \& Cooper, V. (2010). Green IT readiness: A framework and preliminary proof of concept. Australasian Journal of Information Systems, 16(2), 5-23. doi:https://doi.org /10.3127/ajis.v16i2.545

Morgil, İ., Seçil, A., Seçken, N., Yavuz, S., \& Oskay, Ö. Ö. (2004). The influence of computerassisted education on environmental knowledge and environmental awareness. Chemistry Education Research and Practice, 5(2), 99-110. doi:10.1039/B3RP90032K

Muratore, I. (2016). Teens as impulsive buyers: what is the role of price? International Journal of Retail \& Distribution Management, 44(11), 1166-1180. doi:https://doi.org/10.1108/ IJRDM-08-2015-0120

Mutz, D. C. (2011). Population-based survey experiments. Princeton: Princeton University Press.

Nagata, T., Setoguchi, S., Hemenway, D., \& Perry, M. (2008). Effectiveness of a law to reduce alcohol-impaired driving in Japan. Injury Prevention, 14(1), 19-23. doi:http://dx.doi.org/10.1136/ip.2007.015719

Nathanail, E., \& Adamos, G. (2013). Road safety communication campaigns: Research designs and behavioral modeling. Transportation Research Part F: Traffic Psychology and Behaviour, 18, 107-122. doi:https://doi.org/10.1016/j.trf.2012.12.003 
Nemtsov, A. V. (1998). Alcohol-related harm and alcohol consumption in Moscow before, during and after a major anti-alcohol campaign. Addiction, 93(10), 1501-1510. doi: https://doi.org/10.1046/j.1360-0443.1998.931015016.x

Nevo, A., Turner, J. L., \& Williams, J. W. (2016). Usage-based pricing and demand for residential broadband. Econometrica, 84(2), 411-443. doi: https://doi.org/10.3982/ECTA11927

Oguchi, T. (2016). Achieving safe road traffic-the experience in Japan. International Association of Traffic and Safety Sciences, 39(2), 110-116. doi:https://doi.org/10.1016/ j.iatssr.2016.01.003

Olexsak, S. J., \& Meier, A. (2014). The electricity impacts of Earth Hour: An international comparative analysis of energy-saving behavior. Energy Research \& Social Science, 2(1), 159-182. doi:https://doi.org/10.1016/j.erss.2014.04.014

Pedulla, D. S., \& Thébaud, S. (2015). Can we finish the revolution? Gender, work-family ideals, and institutional constraint. American sociological review, 80(1), 116-139. doi:https://doi.org/10.1177/0003122414564008

Petrunoff, N., Rissel, C., Wen, L. M., \& Martin, J. (2015). Carrots and sticks vs carrots: Comparing approaches to workplace travel plans using disincentives for driving and incentives for active travel. Journal of Transport $\mathcal{E}$ Health, 2(4), 563-567. doi:https://doi.org/10.1016/j.jth.2015.06.007

Pooley, J. A., \& o'Connor, M. (2000). Environmental education and attitudes: Emotions and beliefs are what is needed. Environment and Behavior, 32(5), 711-723. doi:https:// doi.org/10.1177/0013916500325007

Pope, D. A., Poe, L., Stein, J. S., Kaplan, B. A., DeHart, W. B., Mellis, A. M., Heckman, B. W., Epstein, L. H., Chaloupka, F. J., \& Bickel, W. K. (2020). The Experimental Tobacco Marketplace: Demand and substitutability as a function of cigarette taxes and e-liquid subsidies. Nicotine and Tobacco Research, 22(5), 782-790. doi:https://doi.org/10.1093/ntr/ ntz116

Poulter, D. R., \& McKenna, F. P. (2010). Evaluating the effectiveness of a road safety education intervention for pre-drivers: An application of the theory of planned behaviour. British Journal of Educational Psychology, 80(2), 163-181. doi: https://doi.org/10.1348/ 014466509 X468421

Priem, R. L., \& Butler, J. E. (2001). Tautology in the resource-based view and the implications of externally determined resource value: Further comments. Academy of Management Review, 26(1), 57-66. doi:https://doi.org/10.5465/amr.2001.4011946

Ranjit, Y. S., Snyder, L. B., Hamilton, M. A., \& Rimal, R. N. (2017). Self-determination theory and risk behavior in a collectivistic society: preventing reckless driving in urban Nepal. Journal of Health Communication, 22(8), 672-681. doi:https://doi.org/10.1080/10810730. 2017.1341569

Rivera, J., \& De Leon, P. (2004). Is greener whiter? Voluntary environmental performance of western ski areas. Policy Studies Journal, 32(3), 417-437. doi:https://doi.org/10.1111/j.15410072.2004.00073.x

Rundmo, T., \& Iversen, H. (2004). Risk perception and driving behaviour among adolescents in two Norwegian counties before and after a traffic safety campaign. Safety science, 42(1), 1-21. doi:https://doi.org/10.1016/S0925-7535(02)00047-4

Sahin, E. (2013). Predictors of Turkish Elementary Teacher Candidates' Energy Conservation Behaviors: An Approach on Value-Belief-Norm Theory. International Journal of Environmental and Science Education, 8(2), 269-283. doi:10.12973/ijese.2013.204a 
Salahuddin, M., \& Alam, K. (2015). Internet usage, electricity consumption and economic growth in Australia: A time series evidence. Telematics and Informatics, 32(4), 862-878. doi:10.1016/j.tele.2015.04.011

Schaap, M. M., Kunst, A. E., Leinsalu, M., Regidor, E., Ekholm, O., Dzurova, D., Helmert, U., Klumbiene, J., Santana, P., \& Mackenbach, J. P. (2008). Effect of nationwide tobacco control policies on smoking cessation in high and low educated groups in 18 European countries. Tobacco Control, 17(4), 248-255. doi:http://dx.doi.org/10.1136/tc.2007.024265

Schlagel, C., \& Sarstedt, M. (2016). Assessing the measurement invariance of the fourdimensional cultural intelligence scale across countries: A composite model approach. European Management Journal, 34(6), 633-649.

Schulz, G. (2016). The green and virtual data center. Boca Raton, Florida, United States: CRC Press.

Sedera, D., Gable, G., \& Chan, T. (2003, July). Survey Design: Insights from a Public Sector ERP Success Story. Paper presented at the 7th Pacific Asia conference on Information Systems, University of South Australia. Retrieved March 05, 2020, from https://eprints.qut.edu.au/24794/1/24794.pdf

Sedera, D., Lokuge, S., Tushi, B., \& Tan, F. (2017). Multi-disciplinary green IT archival analysis: A pathway for future studies. Communications of the Association for Information Systems, 41(1), 674-773. doi:https://doi.org/10.17705/1CAIS.04128

Seidler, A.-R., Henkel, C., Fiedler, M., Kranz, J., Ixmeier, A., \& Strunk, K. S. (2020). Promoting Eco-Sustainable Behavior with Gamification: An Experimental Study on the Alignment of Competing Goals. Paper presented at the Forty-First International Conference on Information Systems, India. Retrieved January 10, 2021, from https://aisel.aisnet.org/icis2020/societal_impact/societal_impact/3

Sen, S., Joe-Wong, C., Ha, S., \& Chiang, M. (2015). Smart data pricing: Using economics to manage network congestion. Communications of the ACM, 58(12), 86-93. doi:10.1145/2756543

Shanock, L. R., Baran, B. E., Gentry, W. A., Pattison, S. C., \& Heggestad, E. D. (2010). Polynomial regression with response surface analysis: A powerful approach for examining moderation and overcoming limitations of difference scores. Journal of Business and Psychology, 25(4), 543-554. doi:https://doi.org/10.1007/s10869-010-9183-4

Sheehan, M., Schonfeld, C., Ballard, R., Schofield, F., Najman, J., \& Siskind, V. (1996). A three year outcome evaluation of a theory based drink driving education program. Journal of Drug Education, 26(3), 295-312. doi:https://doi.org/10.2190/RPRV-7GP1-XH7F-3LHN

Shuja, J., Ahmad, R. W., Gani, A., Ahmed, A. I. A., Siddiqa, A., Nisar, K., Khan, S. U., \& Zomaya, A. Y. (2017). Greening emerging IT technologies: techniques and practices. Journal of Internet Services and Applications, 8(1), 1-11. doi:https://doi.org/10.1186/s13174017-0060-5

Sinha, I., \& Batra, R. (1999). The effect of consumer price consciousness on private label purchase. International Journal of Research in Marketing, 16(3), 237-251. doi:https://doi.org /10.1016/S0167-8116(99)00013-0

Spector, P. E., \& Brannick, M. T. (2011). Methodological urban legends: The misuse of statistical control variables. Organizational Research Methods, 14(2), 287-305. doi:https://doi.org/10.1177/1094428110369842

Statista. (2019). Internet Of Things (IoT) Connected Devices Installed Base Worldwide From 2015 To 2025. Retrieved February 15, 2020, from https://www.statista.com/statistics/ 471264/iot-number-of-connected-devices-worldwide/ 
Steptoe, A., Wardle, J., Cui, W., Baban, A., Glass, K., Pelzer, K., Tsuda, A., \& Vinck, J. (2002). An international comparison of tobacco smoking, beliefs and risk awareness in university students from 23 countries. Addiction, 97(12), 1561-1571. doi: https://doi.org/10.1046/j.1360-0443.2002.00269.x

Stern, P. C. (1999). Information, incentives, and proenvironmental consumer behavior. Journal of Consumer Policy, 22(4), 461-478. doi:https://doi.org/10.1023/A:1006211709570

Stern, P. C. (2000). New environmental theories: toward a coherent theory of environmentally significant behavior. Journal of Social Issues, 56(3), 407-424. doi:10.1111/0022-4537.00175

Stern, P. C., Dietz, T., Abel, T., Guagnano, G. A., \& Kalof, L. (1999). A value-belief-norm theory of support for social movements: The case of environmentalism. Human Ecology Review, 6(2), 81-97.

Syu, F.-K., Huang, M.-Y., \& Huang, J.-J. (2010). A successful intervention to reduce cigarillo use among Baltimore youth. Fooyin Journal of Health Sciences, 2(3-4), 72-84. doi:https://doi.org/10.1016/S1877-8607(11)60002-7

Thilina, D., Guruge, M., \& Nanayakkara, N. (2020). A Descriptive Analysis on Digital Behaviour of Young Adults in Sri Lanka. International Journal of Business and Management Invention, 9(6), 58-67. doi:10.35629/8028-0906055867

Thombs, D. L., \& Osborn, C. J. (2019). Introduction to Addictive Behaviors (3 ed.). New York: The Guilford Press.

UN. (2019). What's the cost of your search? Retrieved January 06, 2020, from https://www.unenvironment.org/news-and-stories/story/whats-cost-your-search

Venkatesh, V., Brown, S. A., Maruping, L. M., \& Bala, H. (2008). Predicting different conceptualizations of system use: the competing roles of behavioral intention, facilitating conditions, and behavioral expectation. Management Information Systems Quarterly, 32(3), 483-502. doi:https://doi.org/10.2307/25148853

Venkatesh, V., \& Goyal, S. (2010). Expectation disconfirmation and technology adoption: polynomial modeling and response surface analysis. Management Information Systems Quarterly, 34(2), 281-303. doi:https://doi.org/10.2307/20721428

Verdonk-Kleinjan, W. M., Candel, M. J., Knibbe, R. A., Willemsen, M. C., \& de Vries, H. (2011). Effects of a workplace-smoking ban in combination with tax increases on smoking in the Dutch population. Nicotine $\mathcal{E}$ Tobacco Research, 13(6), 412-418. doi:https://doi.org/10.1093/ntr/ntr014

Wakefield, K. L., \& Inman, J. J. (2003). Situational price sensitivity: the role of consumption occasion, social context and income. Journal of Retailing, 79(4), 199-212. doi:https://doi.org/10.1016/j.jretai.2003.09.004

Wathuge, A., \& Sedera, D. (2021). An awareness-based model to minimize the environmental damage of the internet usage: A Longitudinal Study. Paper presented at the Pacific Asia Conference on Information Systems, Dubai. Retrieved August 20, 2021, from https://aisel.aisnet.org/pacis2021/130/

Watts, R. L., \& Zimmerman, J. L. (1978). Towards a positive theory of the determination of accounting standards. Accounting Review, 53(1), 112-134.

Whitmarsh, L., \& O'Neill, S. (2010). Green identity, green living? The role of proenvironmental self-identity in determining consistency across diverse proenvironmental behaviours. Journal of Environmental Psychology, 30(3), 305-314. doi:https://doi.org/10.1016/j.jenvp.2010.01.003

Widdicks, K. (2020). Understanding and mitigating the impact of Internet demand in everyday life. Lancaster University. https://doi.org/10.17635/lancaster/thesis/951 
Wold, H. (1989). Theoretical Empiricism. New York, USA: Paragon House.

Yang, S., Zhang, D., \& Li, D. (2019). A Calculation Model for CO2 Emission Reduction of Energy Internet: A Case Study of Yanqing. Sustainability, 11(9), 2502. doi:https://doi.org/10.3390/su11092502

Yucedag, C., Kaya, L. G., \& Cetin, M. (2018). Identifying and assessing environmental awareness of hotel and restaurant employees' attitudes in the Amasra District of Bartin. Environmental Monitoring and Assessment, 190(2), 60. doi:https://doi.org/10.1007/s10661017-6456-7

Zeithaml, V. A. (1988). Consumer perceptions of price, quality, and value: a means-end model and synthesis of evidence. Journal of Marketing, 52(3), 2-22. doi:https://doi.org/10.1177/ 002224298805200302

Zettelmeyer, F., Morton, F. S., \& Silva-Risso, J. (2001). Cowboys or Cowards: Why are Internet car prices lower? National Bureau of Economic Research. Working Paper No. 8667. doi:https://www.nber.org/papers/w8667

Zhang, Y., Wang, Y., \& Wang, X. (2012, September). Electricity bill capping for cloud-scale data centers that impact the power markets. Paper presented at the 41st International Conference on Parallel Processing, Pittsburgh. Retrieved March 06, 2020, from https://ieeexplore.ieee.org/stamp/stamp.jsp?arnumber=6337605\&casa_token=psXLeIXp TjAAAAAA:pL6_GwzfiOa5zw9AXOOAI1rxkbXJvlG4XwT3DDoeqj1XrJECii7nFd4AHn irJVBNqtwWEDy9Lg

Ziadat, A. H. (2010). Major factors contributing to environmental awareness among people in a third world country/Jordan. Environment, Development and Sustainability, 12(1), 135-145. doi:https://doi.org/10.1007/s10668-009-9185-4

Zimmermann, S., Meijer, I., Tiwari, M. K., Paredes, S., Michel, B., \& Poulikakos, D. (2012). Aquasar: A hot water cooled data center with direct energy reuse. Energy, 43(1), 237-245. doi:https://doi.org/10.1016/j.energy.2012.04.037

\section{Appendix - Questionnaire Items}

\section{Environmental Awareness}

Adapted from: (Bulgurcu et al., 2010), (Morgil et al., 2004):

My internet usage can be damaging to the environment.

I am aware of the cost that data centers have on the environment.

I would have liked my internet providers and services to use renewable energy sources.

I save internet data by downloading a song, rather than listening to it online frequently.

Compared to my friends, I spend more time on the Web.

\section{Price Affordability}

Adapted from: (Zeithaml, 1988), (Wakefield \& Inman, 2003), (Sinha \& Batra, 1999):

I am conscious about the price of my internet.

I find the internet services that I use to be affordable.

I am not willing to exert extra effort to find the cheapest internet package.

The money saved by finding a cheaper internet package is not worth the time and effort. Increase of telecommunication tax will never affect my internet usage pattern. 


\section{Internet Usage}

Adapted from: (Mathwick \& Rigdon, 2004), (Venkatesh et al., 2008):

I spend several hours a day on the web.

Compared with most of my friends, I think I spend a lot of time on the Web.

Outside of the time I spend with e-mail, I consider myself to be a "heavy internet user."

I frequently have multiple devices connected to my internet.

I try limiting my time using the internet, but found it challenging.

Copyright: () 2022 authors. This is an open-access article distributed under the terms of the Creative Commons Attribution-NonCommercial 3.0 Australia License, which permits noncommercial use, distribution, and reproduction in any medium, provided the original author and AJIS are credited.

doi: https://doi.org/10.3127/ajis.v26i0.3239

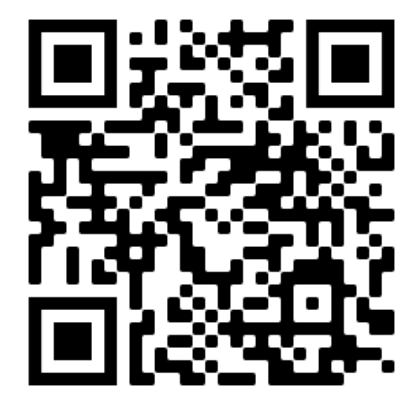

